\title{
Generalised framework of limit equilibrium methods for slope stability analysis
}

\author{
D. Y. ZHU, ${ }^{*}$ C. F. LEE† and H. D. JIANG $†$
}

\begin{abstract}
A generalised framework is proposed in this paper incorporating almost all of the existing limit equilibrium methods of slices for slope stability analysis with general slip surfaces. The force and moment equilibrium equations are derived in terms of the factor of safety and the initially assumed normal stress distribution over the slip surface, multiplied by a modification function involving two auxiliary unknowns. These equations are then analytically solved to yield explicit expressions for the factor of safety. Various assumptions regarding the interslice forces can be transformed into a unified form of expression for the normal stress distribution along the slip surface. An iterative procedure is developed to expedite the convergence of the solution for the factor of safety. Experience to date indicates that the process generally converges within a few iterations. Computation schemes are suggested to avoid numerical difficulty, especially in computing the factor of safety associated with the rigorous Janbu method. The present framework can be readily implemented in a computer program, giving solutions of slope stability associated with a number of conventional methods of slices.
\end{abstract}

KEYWORDS: failure; landslides; limit equilibrium methods; numerical modelling and analysis; slopes
Dans cet exposé nous proposons un cadre de travail généralisé incorporant presque toutes les méthodes d'équilibre limite existantes pour les tranches servant à analyser la stabilité de talus avec des surfaces de glissement générales. Nous avons dérivé les équations d'équilibre de forces et de moment en terme de facteur de sécurité et de la distribution de contrainte normale supposée initialement sur la surface de glissement, multipliée par une fonction de modification faisant intervenir deux inconnues auxiliaires. Nous avons alors résolu ces équations de manière analytique pour obtenir des expressions explicites du facteur de sécurité. Diverses suppositions au sujet des forces entre tranches peuvent être transformées en une forme d'expression unifiée pour la distribution de contrainte normale le long de la surface de glissement. Nous avons développé un procédé itératif pour accélérer la convergence de la solution pour le facteur de sécurité. Les expériences réalisées à ce jour indiquent que le processus converge généralement après quelques itérations. Nous suggérons des plans de calcul pour éviter les difficultés numériques, surtout pour le calcul du facteur de sécurité associé à la rigoureuse méthode de Janbu. Ce cadre de travail peut être mis en uvre facilement dans un programme informatique, donnant des solutions de stabilité de pente associées à un certain nombre de méthodes de tranches conventionnelles.

\section{INTRODUCTION}

Limit equilibrium methods of slices have been widely used for assessing the stability of natural or man-made slopes. During the last century, more than 10 methods of slices based on limit equilibrium were developed dealing with circular or arbitrarily shaped slip surfaces (Duncan, 1996). The common features of limit equilibrium methods are as follows:

(a) The sliding body over the failure surface is divided into a finite number of slices (generally vertical).

(b) The strength of the slip surface is mobilised to the same degree to bring the sliding body into a limiting state.

(c) Assumptions regarding interslice forces are employed to render the problem determinate.

(d) The factor of safety is computed from force or/and moment equilibrium equations.

The existing methods of slices involve various assumptions regarding the interslice force along with various combinations of equilibrium conditions (force or/and moment) con-

Manuscript received 18 January 2002; revised manuscript accepted 29 November 2002.

Discussion on this paper closes 1 November 2003; for further details see $p$. ii.

* Department of Civil Engineering, Nanjing Engineering Institute, Nanjing, Hong Kong.

$\dagger$ Department of Civil Engineering, University of Hong Kong, Hong Kong.

¥ College of Civil Engineering, Hohai University, Nanjing, China. sidered, thus giving different values of factor of safety for the same slip surface. For both practical and theoretical purposes, a generalised framework incorporating the existing methods commonly used in practice is desired in order to examine them against a consistent background, to identify the sources of differences in the computed values of factors of safety, and to justify the margin of reasonable solutions.

Several authors have made an attempt to incorporate the commonly used methods of slices into a generalised framework (Fredlund \& Krahn, 1977; Espinoza et al., 1994). With these approaches, the equations of factor of safety with respect to force and moment equilibrium are derived separately. For non-rigorous methods that do not satisfy the complete equilibrium conditions, only one equation in terms of one unknown (the factor of safety) is to be solved in an iterative manner, and the converged value of factor of safety can generally be obtained within a few iterations. In contrast, for rigorous methods, two equations in terms of factor of safety and an auxiliary unknown are to be solved simultaneously. Owing to the highly non-linear nature of the two equations, relatively complex iterative procedures could be involved, and numerical difficulties may be encountered in some special cases (Ching \& Fredlund, 1983). Note that the term 'rigorous' is used in this paper in a limit equilibrium context, which means that the whole sliding body as well as the vertical slices are in complete equilibrium (Yu et al., 1998; Kim et al., 1999). The term 'non-rigorous' implies incomplete equilibrium for the sliding body or slices.

In this paper, a new framework is formulated to accommodate most of the existing methods of slices, and a more efficient numerical procedure is developed to calculate the 
factor of safety while avoiding the potential numerical difficulties. With this framework, expressions of factor of safety are analytically derived by adjusting the distribution of normal stresses along the slip surface that resulted from the various assumptions about the interslice forces, taking into account all combinations of equilibrium conditions. The computed value of factor of safety is converged within a few iterations, even for the rigorous Janbu method, with which non-convergence is often encountered in solution by conventional procedures.

\section{GENERALISED FORMULATION}

Basic equations of equilibrium

A typical slope profile with a general-shaped slip surface is presented in Fig. 1(a). Note that circular slip surfaces are also taken as general surfaces in this framework, for general purposes. The two-dimensional problem is analysed herein. Thus the cross-section of the slope is visualised as having a unit length. The sliding body is bounded by the ground surface $y=g(x)$ and the slip surface $y=s(x)$. By assigning a constant factor of safety, $F_{\mathrm{s}}$, to the whole failure surface,

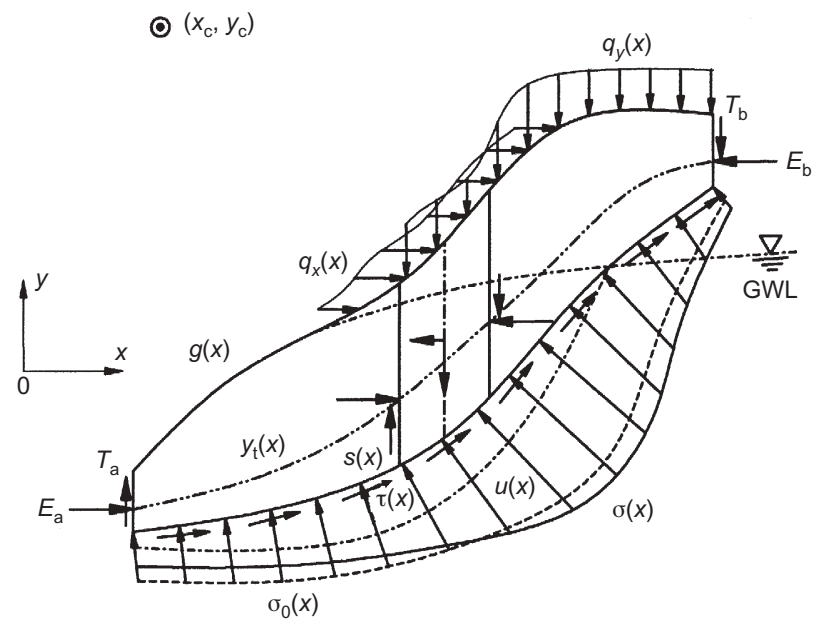

(a)

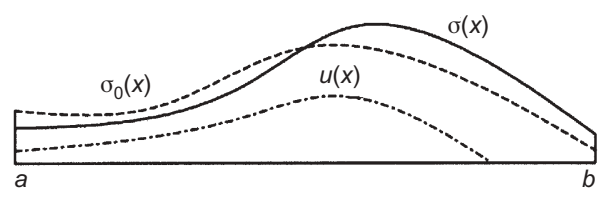

(b)

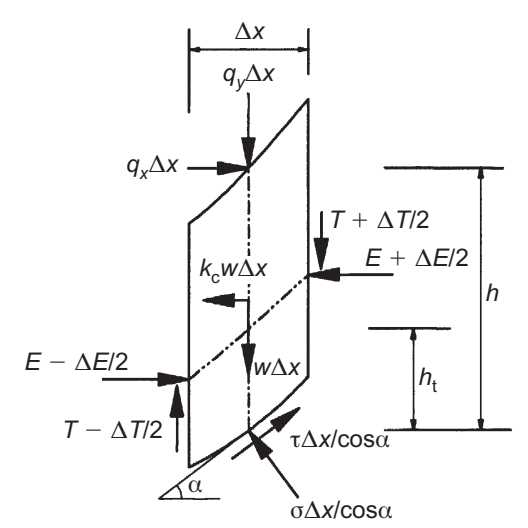

(c)

Fig. 1. Geometry of slope and notations: (a) sliding mass; (b) normal stresses over the slip surface; (c) typical slice the sliding body is brought into a limiting state under the combined action of self-weight $w(x)$ (that is, the weight of a slice of unit width), horizontal seismic force $k_{\mathrm{c}} w(x)$ (where $k_{\mathrm{c}}$ is the horizontal seismic coefficient), pore water pressure $u(x)$ at the base, horizontal and vertical surcharges or reinforced pressures $q_{x}(x)$ and $q_{y}(x)$ (where $q_{x}(x)$ and $q_{y}(x)$ are defined respectively as the vertical and horizontal loads acting on the ground per unit width of the sliding body), and horizontal and vertical end forces $E_{\mathrm{a}}, T_{\mathrm{a}}, E_{\mathrm{b}}$ and $T_{\mathrm{b}}$, acting on the left and right ends of the slip surface respectively. The end forces may be the resultant of water pressure on the tension crack at the upper end of the slope, or lateral forces supported by any retaining structure at the toe of the slope. Line loads acting on the slope are not included but can be transformed into distributed pressures of some appropriate intensity. The horizontal and vertical internal forces acting on the interface cutting the sliding body vertically are $E(x)$ and $T(x)$ respectively, and the point of action of $E(x)$ lies along the line of thrust $y_{\mathrm{t}}(x)$. The normal and tangential stresses on the slip surface are $\sigma(x)$ and $\tau(x)$ respectively. The Mohr-Coulomb failure criterion, in terms of effective stresses, is given by

$$
\tau(x)=\frac{1}{F_{\mathrm{s}}}\{[\sigma(x)-u(x)] \tan \phi(x)+c(x)\}
$$

where $\phi(x)$ and $c(x)$ are the effective internal friction angle and cohesion on the slip surface respectively. Note that if a total stress analysis is used where $u(x)$ is set equal to zero, $\phi(x)$ and $c(x)$ would refer to the strength parameters in terms of total stress. Moreover, $\tan \phi(x)$ will be labelled as $\psi(x)$ hereafter. For simplicity, the symbol ' $(x)$ ' associated with the various quantities (taken as functions of $x$ ) in this paper will be omitted in the following presentations. Thus the above equation is reduced to

$$
\tau=\frac{1}{F_{\mathrm{s}}}(\sigma \cdot \psi-u \cdot \psi+c)
$$

At this stage the normal stress distribution $\sigma(x)$ is assumed to be prescribed, as shown in Fig. 1(a) and (b). For the sliding body, there are three equations of equilibrium: the horizontal force equilibrium equation, the vertical force equilibrium equation and the moment equilibrium equation. With reference to Fig. 1(c), which shows the forces acting on a typical slice, and selecting a reference point $\left(x_{\mathrm{c}}, y_{\mathrm{c}}\right)$ as the centre of moment, one can derive the equilibrium equations as

$$
\begin{aligned}
& \int_{a}^{b}\left(-\sigma \cdot s^{\prime}+\tau-k_{\mathrm{c}} w+q_{x}\right) \mathrm{d} x=E_{\mathrm{b}}-E_{\mathrm{a}} \\
& \int_{a}^{b}\left(\sigma+\tau \cdot s^{\prime}-w-q_{y}\right) \mathrm{d} x=T_{\mathrm{b}}-T_{\mathrm{a}} \\
& \int_{a}^{b}\left[\left(-\sigma \cdot s^{\prime}+\tau\right) \cdot\left(y_{\mathrm{c}}-s\right)+\left(\sigma+\tau \cdot s^{\prime}-w-q_{y}\right) \cdot\left(x-x_{\mathrm{c}}\right)\right. \\
& \left.\quad-k_{\mathrm{c}} w\left(y_{\mathrm{c}}-0 \cdot 5 s-0 \cdot 5 g\right)+q_{x}\left(y_{\mathrm{c}}-g\right)\right] \mathrm{d} x \\
& =T_{\mathrm{b}}\left(b-x_{\mathrm{c}}\right)+E_{\mathrm{b}}\left(y_{\mathrm{c}}-y_{\mathrm{tb}}\right)-T_{\mathrm{a}}\left(a-x_{\mathrm{c}}\right)-E_{\mathrm{a}}\left(y_{\mathrm{c}}-y_{t \mathrm{a}}\right)
\end{aligned}
$$

where $s^{\prime}(x)=\mathrm{d} s(x) / \mathrm{d} x=\tan \alpha(x), \alpha(x)$ is the inclination of the slip surface at $x$, and $y_{\mathrm{ta}}$ and $y_{\mathrm{tb}}$ are ordinates of the points of action of $E_{\mathrm{a}}$ and $E_{\mathrm{b}}$ respectively.

Let

$$
\begin{aligned}
& F_{x}=\int_{a}^{b}\left(k_{\mathrm{c}} w-q_{x}\right) \mathrm{d} x+E_{\mathrm{b}}-E_{\mathrm{a}} \\
& F_{y}=\int_{a}^{b}\left(w+q_{y}\right) \mathrm{d} x+T_{\mathrm{b}}-T_{\mathrm{a}}
\end{aligned}
$$




$$
\begin{aligned}
M_{\mathrm{c}}= & \int_{a}^{b}\left[k_{\mathrm{c}} w\left(y_{\mathrm{c}}-0.5 s-0.5 g\right)-q_{x}\left(y_{\mathrm{c}}-g\right)\right. \\
& \left.+\left(w+q_{y}\right)\left(x-x_{\mathrm{c}}\right)\right] \mathrm{d} x \\
& +T_{\mathrm{b}}\left(b-x_{\mathrm{c}}\right)+E_{\mathrm{b}}\left(y_{\mathrm{c}}-y_{\mathrm{tb}}\right)-T_{\mathrm{a}}\left(a-x_{\mathrm{c}}\right) \\
& -E_{\mathrm{b}}\left(y_{\mathrm{c}}-y_{\mathrm{ta}}\right)
\end{aligned}
$$

and

$$
\begin{aligned}
& r_{\sigma}(x)=-s^{\prime} \cdot\left(y_{\mathrm{c}}-s\right)+x-x_{\mathrm{c}} \\
& r_{\tau}(x)=y_{\mathrm{c}}-s+s^{\prime}\left(x-x_{\mathrm{c}}\right)
\end{aligned}
$$

The previous equations of equilibrium can be reduced to

$$
\begin{aligned}
& -\int_{a}^{b} \sigma \cdot s^{\prime} \mathrm{d} x+\int_{a}^{b} \tau \mathrm{d} x=F_{x} \\
& \int_{a}^{b} \sigma \mathrm{d} x+\int_{a}^{b} \tau \cdot s^{\prime} \mathrm{d} x=F_{y} \\
& \int_{a}^{b} \sigma \cdot r_{\sigma} \mathrm{d} x+\int_{a}^{b} \tau \cdot r_{\tau} \mathrm{d} x=M_{\mathrm{c}}
\end{aligned}
$$

Substituting equation (1) into the above equations, the equations of equilibrium become

$$
\begin{gathered}
\int_{a}^{b} \sigma \cdot\left(-s^{\prime}+\psi \frac{1}{F_{\mathrm{s}}}\right) \mathrm{d} x=F_{x}+\frac{1}{F_{\mathrm{s}}} \int_{a}^{b}(u \psi-c) \mathrm{d} x \\
\left.\int_{a}^{b} \sigma \cdot\left(1+s^{\prime} \psi \frac{1}{F_{\mathrm{S}}}\right) \mathrm{d} x=F_{y}+\frac{1}{F_{\mathrm{s}}} \int_{a}^{b} s^{\prime}(u \psi-c) \mathrm{d} x\right) \\
F_{\mathrm{s}}=\frac{\int_{a}^{b} \sigma \psi r_{\tau} \mathrm{d} x+\int_{a}^{b}(-u \psi+c) r_{\tau} \mathrm{d} x}{M_{\mathrm{c}}-\int_{a}^{b} \sigma r_{\sigma} \mathrm{d} x}
\end{gathered}
$$

Function modifying normal stresses on the slip surface

All methods of slices feature more than one equilibrium condition, except the Ordinary method (Fellenius, 1936). In other words, two or three equations of equilibrium are used to determine the factor of safety. Therefore auxiliary unknowns should be introduced to render the number of unknowns compatible with the number of equations. On the other hand, the normal stress distribution $\sigma(x)$ still remains unknown. This, however, provides a way of introducing the auxiliary unknowns. At first, we can initially assume a normal stress distribution $\sigma_{0}(x)$, the methodology for which will be discussed later in the paper. This assumed $\sigma_{0}(x)$, together with any assumed value of $F_{\mathrm{s}}$, would not satisfy the required equations of equilibrium. Then $\sigma_{0}(x)$ is multiplied by a modifying function $\xi(x)$ to meet this requirement:

$$
\sigma(x)=\xi(x) \sigma_{0}(x)
$$

For rigorous limit equilibrium methods that satisfy all equilibrium conditions, the modifying function should involve two auxiliary unknowns to make the problem determinate. The form of $\xi(x)$ is suggested as

$$
\xi(x)=\eta_{1} \xi_{1}(x)+\eta_{2} \xi_{2}(x)
$$

For simplicity, $\xi(x)$ is taken as a linear function: that is,

$$
\xi(x)=\eta_{1} \frac{x-b}{a-b}+\eta_{2} \frac{x-a}{b-a}
$$

where $\eta_{1}$ and $\eta_{2}$ represent the magnitude of the modifying function at the left and right ends of the slip surface respectively.

Comparing equations (7) and (8), we have

$$
\begin{aligned}
& \xi_{1}(x)=\frac{x-b}{a-b} \\
& \xi_{2}(x)=\frac{x-a}{b-a}
\end{aligned}
$$

For most non-rigorous methods where two equilibrium conditions are considered, only one auxiliary unknown should be involved. The normal stress distribution $\sigma(x)$ can be also described by equations (6) and (8) except that

$$
\eta_{1}=\eta_{2}
$$

For the Ordinary method in which only moment equilibrium condition is considered, no auxiliary unknown is required. This is identical to assuming

$$
\begin{aligned}
& \eta_{1}=1 \\
& \eta_{2}=1
\end{aligned}
$$

with the normal stress distribution $\sigma(x)$ being described by equations (6) and (8) as well.

\section{Solutions for factor of safety}

Substituting equations (6) and (7) into equations (5a), (5b) and $(5 \mathrm{c})$, one obtains

$$
\begin{gathered}
\eta_{1} \int_{a}^{b} \sigma_{0} \xi_{1} \cdot\left(-s^{\prime}+\psi \frac{1}{F_{\mathrm{s}}}\right) \mathrm{d} x+\eta_{2} \int_{a}^{b} \sigma_{0} \xi_{2} \cdot\left(-s^{\prime}+\psi \frac{1}{F_{\mathrm{s}}}\right) \\
\mathrm{d} x=F_{x}+\frac{1}{F_{\mathrm{s}}} \int_{a}^{b}(u \psi-c) \mathrm{d} x \\
\eta_{1} \int_{a}^{b} \sigma_{0} \xi_{1} \cdot\left(1+s^{\prime} \psi \frac{1}{F_{\mathrm{s}}}\right) \mathrm{d} x+\eta_{2} \int_{a}^{b} \sigma_{0} \xi_{2} \cdot\left(1+s^{\prime} \psi \frac{1}{F_{\mathrm{s}}}\right) \\
\mathrm{d} x=F_{y}+\frac{1}{F_{\mathrm{s}}} \int_{a}^{b} s^{\prime}(u \psi-c) \mathrm{d} x \\
\eta_{1} \int_{a}^{b} \sigma_{0} \xi_{1} \psi r_{\tau} \mathrm{d} x+\eta_{2} \int_{a}^{b} \sigma_{0} \xi_{2} \psi r_{\tau} \mathrm{d} x \\
+\int_{a}^{b}(-u \psi+c) r_{\tau} \mathrm{d} x \\
M_{\mathrm{c}}-\eta_{1} \int_{a}^{b} \sigma_{0} \xi_{1} r_{\sigma} \mathrm{d} x-\eta_{2} \int_{a}^{b} \sigma_{0} \xi_{2} r_{\sigma} \mathrm{d} x
\end{gathered}
$$

These equations are rearranged as

$$
\begin{aligned}
& \eta_{1} \cdot\left(A_{1}+\frac{1}{F_{\mathrm{s}}} A_{1}^{\prime}\right)+\eta_{2} \cdot\left(A_{2}+\frac{1}{F_{\mathrm{s}}} A_{2}^{\prime}\right)=A_{3}+\frac{1}{F_{\mathrm{s}}} A_{3}^{\prime} \\
& \eta_{1} \cdot\left(B_{1}+\frac{1}{F_{\mathrm{s}}} B_{1}^{\prime}\right)+\eta_{2} \cdot\left(B_{2}+\frac{1}{F_{\mathrm{s}}} B_{2}^{\prime}\right)=B_{3}+\frac{1}{F_{\mathrm{s}}} B_{3}^{\prime} \\
& F_{\mathrm{s}}=\frac{D_{1} \eta_{1}+D_{2} \eta_{2}+D_{3}}{E_{1} \eta_{1}+E_{2} \eta_{2}+E_{3}}
\end{aligned}
$$

where the relevant parameters included in these equations are given in Appendix 1.

Four cases of combination of equilibrium conditions are considered in the existing methods of slices. These are:

(a) both vertical and horizontal force and moment equilibrium conditions

(b) vertical force and moment (about a specified centre) equilibrium conditions

(c) vertical and horizontal force equilibrium conditions

(d) moment equilibrium (about a specified centre) condition. 
These four cases are considered separately in the following:

Case (a). The factor of safety $F_{\mathrm{s}}$ along with the two auxiliary unknowns $\eta_{1}$ and $\eta_{2}$ are determined by solving equations (14a), (14b) and (14c) simultaneously.

Solving equations (14a) and (14b) for $\eta_{1}$ and $\eta_{2}$, one obtains

$$
\begin{aligned}
\eta_{1}=\frac{\left(A_{3} B_{2}-A_{2} B_{3}\right)}{+}+\frac{1}{F_{\mathrm{s}}}\left(A_{3} B_{2}^{\prime}+A_{3}^{\prime} B_{2}-A_{2} B_{3}^{\prime}-A_{2}^{\prime} B_{3}\right) \\
+\frac{1}{F_{\mathrm{s}}^{2}}\left(A_{3}^{\prime} B_{2}^{\prime}-A_{2}^{\prime} B_{3}^{\prime}\right) \\
+\frac{1}{F_{\mathrm{s}}^{2}}\left(A_{1}^{\prime} B_{2}^{\prime}-A_{2}^{\prime} B_{1}^{\prime}\right) \\
\eta_{2}=\frac{(15 \mathrm{a})}{\left(A_{1} B_{1}\right)+\frac{1}{F_{\mathrm{s}}}\left(A_{1} B_{2}^{\prime}+A_{1}^{\prime} B_{2}-A_{2} B_{1}^{\prime}-A_{2}^{\prime} B_{1}\right)} \\
+\frac{1}{F_{\mathrm{s}}^{2}}\left(A_{1}^{\prime} B_{3}^{\prime}-A_{3}^{\prime} B_{1}^{\prime}\right) \\
+\frac{1}{\left.F_{\mathrm{s}}-A_{2} B_{1}\right)+\frac{1}{F_{\mathrm{s}}}\left(A_{1} B_{2}^{\prime}+A_{1}^{\prime} B_{2}-A_{2} B_{1}^{\prime}-A_{2}^{\prime} B_{1}\right)}
\end{aligned}
$$

The two equations can be rewritten as

$$
\begin{array}{r}
\eta_{1}=\frac{T_{0}+\frac{1}{F_{\mathrm{s}}} T_{1}+\frac{1}{F_{\mathrm{s}}^{2}} T_{2}}{G_{0}+\frac{1}{F_{\mathrm{s}}} G_{1}+\frac{1}{F_{\mathrm{s}}^{2}} G_{2}} \\
\eta_{2}=\frac{S_{0}+\frac{1}{F_{\mathrm{s}}} S_{1}+\frac{1}{F_{\mathrm{s}}^{2}} S_{2}}{G_{0}+\frac{1}{F_{\mathrm{s}}} G_{1}+\frac{1}{F_{\mathrm{s}}^{2}} G_{2}}
\end{array}
$$

where the relevant parameters are given in Appendix 1.

Substituting equations (16a) and (16b) into equation (14c) results in

$$
\begin{gathered}
\left(D_{1} T_{0}+D_{2} S_{0}+D_{3} G_{0}\right)+\frac{1}{F_{\mathrm{s}}}\left(D_{1} T_{1}+D_{2} S_{1}+D_{3} G_{1}\right) \\
F_{\mathrm{s}}=\frac{1+\frac{1}{F_{\mathrm{s}}^{2}}\left(D_{1} T_{2}+D_{2} S_{2}+D_{3} G_{2}\right)}{\left(E_{1} T_{0}+E_{2} S_{0}+E_{3} G_{0}\right)+\frac{1}{F_{\mathrm{s}}}\left(E_{1} T_{1}+E_{2} S_{1}+E_{3} G_{1}\right)} \\
+\frac{1}{F_{\mathrm{s}}^{2}}\left(E_{1} T_{2}+E_{2} S_{2}+E_{3} G_{2}\right)
\end{gathered}
$$

which reduces to a cubic equation in terms of $F_{\mathrm{s}}$ :

$$
F_{\mathrm{s}}^{3}+t_{2} F_{\mathrm{s}}^{2}+t_{1} F_{\mathrm{s}}+t_{0}=0
$$

where parameters $t_{0}, t_{1}$ and $t_{2}$ are given in Appendix 1 .

Equation (18) is rewritten as

$$
\left(F_{\mathrm{s}}-\frac{t_{2}}{3}\right)^{3}+p\left(F_{\mathrm{s}}-\frac{t_{2}}{3}\right)+q=0
$$

where parameters $p$ and $q$ are given in Appendix 1 .

Equation (19) has three analytical roots. The real root of significance is

$$
\begin{aligned}
F_{\mathrm{s}}^{(\mathrm{hvm})}= & \frac{t_{2}}{3}+\sqrt[3]{-\frac{q}{2}+\sqrt{\left(\frac{q}{2}\right)^{2}+\left(\frac{p}{3}\right)^{3}}} \\
& +\sqrt[3]{-\frac{q}{2}-\sqrt{\left(\frac{q}{2}\right)^{2}+\left(\frac{p}{3}\right)^{3}}}
\end{aligned}
$$

The superscript (hvm) means that the solution for factor of safety satisfies horizontal and vertical force equilibrium as well as moment equilibrium conditions.

Case (b). In this case, vertical force equilibrium equation (14b) and moment equilibrium equation (14c) along with equation (10) are combined to determine $F_{\mathrm{s}}$ and $\eta_{1}\left(=\eta_{2}\right)$. From these equations, one readily obtains

$$
\begin{aligned}
& \eta_{1}=\frac{F_{\mathrm{s}} B_{3}+B_{3}^{\prime}}{F_{\mathrm{s}}\left(B_{1}+B_{2}\right)+B_{1}^{\prime}+B_{2}^{\prime}} \\
& \eta_{1}=\frac{-F_{\mathrm{s}} E_{3}+D_{3}}{F_{\mathrm{s}}\left(E_{1}+E_{2}\right)-D_{1}-D_{2}}
\end{aligned}
$$

Combination of the two equations results in a quadratic equation in terms of $F_{\mathrm{s}}$ :

$$
F_{\mathrm{s}}^{2}+p_{1} F_{\mathrm{s}}+q_{1}=0
$$

where $p_{1}$ and $q_{1}$ are given in Appendix 1 .

Equation (22) has two roots. For slope stability problems, no two distinct factors of safety exist to bring the potential sliding mass into a limiting state. Therefore equation (22) has one positive root and one negative root, or double positive roots. The root of physical significance is

$$
F_{\mathrm{s}}^{(\mathrm{vm})}=-\frac{p_{1}}{2}+\sqrt{\left(\frac{p_{1}}{2}\right)^{2}-q_{1}}
$$

The superscript (vm) means that the solution for factor of safety has taken into account the vertical force and moment (about a specified centre) equilibrium conditions. It must be pointed out that, strictly speaking, moment equilibrium could not be satisfied in the event of incomplete satisfaction of force equilibrium. Hence in this paper we note that this method considers (but not satisfies) moment equilibrium.

Case (c). Horizontal and vertical force equilibrium equations (14a) and (14b) along with equation (10) are combined to determine $F_{\mathrm{s}}$ and $\eta_{1}\left(=\eta_{2}\right)$. From these equations, one obtains

$$
\begin{aligned}
& \eta_{1}=\frac{F_{\mathrm{s}} A_{3}+A_{3}^{\prime}}{F_{\mathrm{s}}\left(A_{1}+A_{2}\right)+A_{1}^{\prime}+A_{2}^{\prime}} \\
& \eta_{1}=\frac{F_{\mathrm{s}} B_{3}+B_{3}^{\prime}}{F_{\mathrm{s}}\left(B_{1}+B_{2}\right)+B_{1}^{\prime}+B_{2}^{\prime}}
\end{aligned}
$$

Combination of the two equations results in a quadratic equation in terms of $F_{\mathrm{s}}$ :

$$
F_{\mathrm{s}}^{2}+p_{2} F_{\mathrm{s}}+q_{2}=0
$$

where $p_{2}$ and $q_{2}$ are given in Appendix 1 .

The significant root of equation (25) is

$$
F_{\mathrm{s}}^{(\mathrm{hv})}=-\frac{p_{2}}{2}+\sqrt{\left(\frac{p_{2}}{2}\right)^{2}-q_{2}}
$$

The superscript (hv) means that the solution for factor of safety satisfies both horizontal and vertical force equilibrium conditions.

Case (d). In this case, only moment equilibrium is considered. Thus equation (14c) along with the relation 
$\eta_{1}=\eta_{2}=1$ is used to determine the factor of safety as follows:

$$
F_{\mathrm{s}}^{(\mathrm{m})}=\frac{D_{1}+D_{2}+D_{3}}{E_{1}+E_{2}+E_{3}}
$$

The superscript $(\mathrm{m})$ means that the solution for factor of safety considers moment equilibrium condition about a specified centre.

\section{INITIALLY ASSUMED NORMAL STRESS $\sigma_{0}(x)$}

Referring to Fig. 1(c) again, one can assume that the normal and shear stresses on the base of the slice are $\sigma_{0}(x)$ and $\tau_{0}(x)$ respectively, and the factor of safety is assumed to be equal to $F_{\mathrm{s} 0}$. Combining the force equilibrium for the slice with its width approaching infinitesimal, we have

$$
\begin{gathered}
-\sigma_{0} s^{\prime}+\tau_{0}-k_{c} w+q_{x}=\frac{\mathrm{d} E}{\mathrm{~d} x} \\
\sigma_{0}+\tau_{0} s^{\prime}-w-q_{y}=\frac{\mathrm{d} T}{\mathrm{~d} x}
\end{gathered}
$$

and the Mohr-Coulomb failure criterion

$$
\tau_{0}=\frac{1}{F_{\mathrm{s} 0}}[\psi(\sigma-u)+c]
$$

Thus

$$
\begin{aligned}
& \sigma_{0}\left(s^{\prime}-\psi_{0}\right)+k_{\mathrm{c}} w-q_{\mathrm{x}}+u \psi_{0}-c_{0}=-\frac{\mathrm{d} E}{\mathrm{~d} x} \\
& \sigma_{0}\left(1+\psi_{0} s^{\prime}\right)-w-q_{y}-\left(u \psi_{0}-c_{0}\right) s^{\prime}=\frac{\mathrm{d} T}{\mathrm{~d} x}
\end{aligned}
$$

where $\psi_{0}=\tan \phi / F_{\mathrm{s} 0}, c_{0}=c / F_{\mathrm{s} 0}$.

As will be indicated later, the conventional assumptions regarding the interslice force employed by the existing methods of slices can be expressed in a general form:

$$
T(x)=\Gamma_{1}(x) E(x)+\Gamma_{2}(x)
$$

where $\Gamma_{1}(x)$ and $\Gamma_{2}(x)$ are dependent upon the assumption used.

From equation (29), we have

$$
\frac{\mathrm{d} T}{\mathrm{~d} x}=\Gamma_{1}(x) \frac{\mathrm{d} E}{\mathrm{~d} x}+E \cdot \Gamma_{1}^{\prime}(x)+\Gamma_{2}^{\prime}(x)
$$

Combining of equations (28a) and (28b) with equation (30) yields

$$
\sigma_{0}=\frac{\begin{array}{c}
w+q_{y}+\left(u \psi_{0}-c_{0}\right) s^{\prime}+\Gamma_{1}\left(q_{x}-k_{\mathrm{c}} \mathrm{W}-u \psi_{0}+c_{0}\right) \\
+E \cdot \Gamma_{1}^{\prime}+\Gamma_{2}^{\prime}
\end{array}}{1+\psi_{0} s^{\prime}+\Gamma_{1}\left(s^{\prime}-\psi_{0}\right)}
$$

In this paper, a total of 12 methods of slices commonly used in practice are examined. These methods are summarised in Table 1 and briefly reviewed in the following, with special regard to the determination of $\Gamma_{1}(x)$ and $\Gamma_{2}(x)$ and their derivatives in equation (31).

\section{Ordinary method (Fellenius, 1936)}

This method is the simplest of all, involving the coarsest assumption regarding the interslice forces. With this method, the interslice forces are neglected when deriving the normal stress on the slip surface:

$$
E=0, T=0
$$

By using this assumption, we can directly derive the expression for $\sigma_{0}(x)$ based on force equilibrium in the direction normal to the base of the slice:

$$
\sigma_{0}=\frac{w+q_{y}+\left(q_{x}-k_{\mathrm{c}} w\right) s^{\prime}}{1+\left(s^{\prime}\right)^{2}}
$$

For generalisation purposes, $\sigma_{0}(x)$ is still described by equation (31) with related parameters as follows:

$$
\begin{aligned}
& \Gamma_{1}(x)=s^{\prime}(x), \Gamma_{2}(x)=0 \\
& \Gamma_{1}^{\prime}(x)=0, \Gamma_{2}^{\prime}(x)=0
\end{aligned}
$$

The Ordinary method conventionally applies to circular slip surfaces and considers moment equilibrium about the centre of the circle. For a non-circular slip surface, the factor of safety can also be computed using the Ordinary method with the centre of moment being taken as the centre of a circle enveloping the slip surface, but the value is for reference purposes only.

\section{Simplified Bishop method (Bishop, 1955)}

This method assumes the interslice forces are horizontal: that is,

$$
T(x)=0
$$

Hence

$$
\begin{aligned}
& \Gamma_{1}(x)=0, \Gamma_{2}(x)=0 \\
& \Gamma_{1}^{\prime}(x)=0, \Gamma_{2}^{\prime}(x)=0
\end{aligned}
$$

This method was originally developed to analyse the stability of circular slip surfaces with vertical force equilibrium and moment equilibrium about the centre taken into consideration. The simplified Bishop method can also be extended to slip surfaces of general shape, with the centre of moment chosen as the centre of a circle nearly approximating the slip surface (Nonveiller, 1965).

\section{Simplified Janbu method (Janbu et al., 1956)}

With this method, the shear interslice force is also assumed to be zero. Therefore equations (34) and (35) apply as well. The simplified Janbu method meets the requirement of vertical and horizontal force equilibrium for the potential sliding mass.

\section{Corps of Engineers Method (US Army Corps of Engineers, 1967)}

This method assumes that the inclination of the interslice force is parallel to that of the ground surface and considers vertical and horizontal force equilibrium conditions; that is,

$$
T(x)=g^{\prime}(x) \cdot E(x)
$$

$\Gamma_{1}(x)$ and $\Gamma_{2}(x)$ are given as follows:

$$
\Gamma_{1}(x)=g^{\prime}(x), \Gamma_{2}(x)=0
$$

where $g^{\prime}(x)$ is the average slope of the ground surface. Their derivatives are, respectively,

$$
\Gamma_{1}^{\prime}(x)=\frac{\Delta \Gamma_{1}(x)}{\Delta x}, \Gamma_{2}^{\prime}(x)=0
$$

In practical computations, the derivative of $\Gamma_{1}(x)$ or $\Gamma_{2}(x)$ is numerically computed using the finite difference method.

\section{Lowe-Karafiath method (Lowe \& Karafiath, 1960)}

This method also considers horizontal and vertical force equilibrium, and assumes that the inclination of interslice force is equal to the mean of the slopes of the ground surface and the slip surface: that is, 


$$
\begin{aligned}
T(x) & =\frac{1}{2}\left[g^{\prime}(x)+s^{\prime}(x)\right] \cdot E(x) \\
\Gamma_{1}(x) & =\frac{1}{2}\left[g^{\prime}(x)+s^{\prime}(x)\right], \Gamma_{2}(x)=0 \\
\Gamma_{1}^{\prime}(x) & =\frac{\Delta \Gamma_{1}(x)}{\Delta x}, \Gamma_{2}^{\prime}(x)=0
\end{aligned}
$$

\section{Sarma method I (Sarma, 1979)}

This method assumes that the shear strength on the interface between adjacent slices is mobilised to the same degree as the failure surface. Vertical and horizontal force equilibrium is taken into account. The relationship between the shear and normal forces is thus given as follows:

$$
T(x)=\left[E(x)-P_{\mathrm{w}}(x)\right] \psi_{0}^{\mathrm{v}}(x)+c_{0}^{\mathrm{v}}(x) h(x)
$$

where $\psi_{0}^{\mathrm{v}}=\tan \phi^{\mathrm{v}} / F_{\mathrm{s} 0}, c_{0}^{\mathrm{v}}=c^{\mathrm{v}} / F_{\mathrm{s} 0}, \tan \phi^{\mathrm{v}}$ and $c^{\mathrm{v}}$ are the weighted average internal friction coefficient and cohesion for the vertical slice interface respectively, and $P_{\mathrm{w}}$ is the resultant of hydrostatic pressure on the interface. From equation (40) we have

$$
\begin{aligned}
& \Gamma_{1}(x)=\psi_{0}^{\mathrm{v}}(x), \Gamma_{2}(x)=-P_{\mathrm{w}}(x) \psi_{0}^{\mathrm{v}}(x)+c_{0}^{\mathrm{v}}(x) h(x) \\
& \Gamma_{1}^{\prime}(x)=\frac{\Delta \Gamma_{1}(x)}{\Delta x}, \Gamma_{2}^{\prime}(x)=\frac{\Delta \Gamma_{2}(x)}{\Delta x}
\end{aligned}
$$

Note that the Sarma (1979) method can consider nonvertical slices, which is beyond the scope of the present framework.

\section{Spencer method (Spencer, 1967, 1973)}

This method assumes that the inclination of the interslice force is a constant, its magnitude being modified to bring the sliding mass into rigorous limiting equilibrium. With this method, we have

$$
\begin{aligned}
& T(x)=\lambda E(x) \\
& \Gamma_{1}(x)=\lambda, \Gamma_{2}(x)=0 \\
& \Gamma_{1}^{\prime}(x)=0, \Gamma_{2}^{\prime}(x)=0
\end{aligned}
$$

where $\lambda$ is a constant (referred to as the scaling parameter) to be determined in the process of computation.

8. Morgenstern-Price method (Morgenstern \& Price, 1965)

This rigorous method assumes that the relationship between the shear and normal interslice forces is as follows:

$$
T(x)=\lambda f(x) E(x)
$$

where $f(x)$ is a prescribed function (called the interslice force function) and $\lambda$ is a scaling parameter. Therefore

$$
\begin{aligned}
& \Gamma_{1}(x)=\lambda f(x), \Gamma_{2}(x)=0 \\
& \Gamma_{1}^{\prime}(x)=\frac{\Delta \Gamma_{1}(x)}{\Delta x}, \Gamma_{2}^{\prime}(x)=0
\end{aligned}
$$

\section{Sarma method II (Sarma, 1973)}

The underlying concept of this method originates from Sarma (1973). The relationship between the shear and normal interslice force is similar to equation (40) in form, except that a scaling parameter $(\lambda)$ is included to render the method within a rigorous context:

$$
T(x)=\lambda\left\{\left[E(x)-P_{\mathrm{w}}(x)\right] \psi_{0}^{\mathrm{v}}(x)+c_{0}^{\mathrm{v}}(x) h(x)\right\}
$$

Then

$$
\begin{aligned}
& \Gamma_{1}(x)=\lambda \psi_{0}^{\mathrm{v}}(x), \Gamma_{2}(x)=\lambda\left[-P_{\mathrm{w}}(x) \psi_{0}^{\mathrm{v}}(x)+c_{0}^{\mathrm{v}}(x) h(x)\right] \\
& \Gamma_{1}^{\prime}(x)=\frac{\Delta \Gamma_{1}(x)}{\Delta x}, \Gamma_{2}^{\prime}(x)=\frac{\Delta \Gamma_{2}(x)}{\Delta x}
\end{aligned}
$$

Note that in the original method of Sarma (1973), the normal interslice force $E(x)$ in equation (46) is expressed as $0.5 k^{\prime} \gamma h^{2}$, which is conceptually identical to $E(x)$, where $k^{\prime}$ is a complex coefficient derived approximately on the basis of plasticity theory and some ideal hypotheses.

\section{Sarma method III (Sarma, 1973)}

This approach is an extension of the above method, for which

$$
\begin{aligned}
T(x) & =\lambda f(x)\left\{\left[E(x)-P_{\mathrm{w}}(x)\right] \psi_{0}^{\mathrm{v}}(x)+c_{0}^{\mathrm{v}}(x) h(x)\right\} \\
\Gamma_{1}(x) & =\lambda f(x) \psi_{0}^{\mathrm{v}}(x), \Gamma_{2}(x) \\
& =\lambda f(x)\left[-P_{\mathrm{w}}(x) \psi_{0}^{\mathrm{v}}(x)+c_{0}^{\mathrm{v}}(x) h(x)\right] \\
\Gamma_{1}^{\prime}(x) & =\frac{\Delta \Gamma_{1}(x)}{\Delta x}, \Gamma_{2}^{\prime}(x)=\frac{\Delta \Gamma_{2}(x)}{\Delta x}
\end{aligned}
$$

where $f(x)$ is a dimensionless shape function.

\section{Correia method (Correia, 1988)}

This method assumes that the shear interslice force can be described by a function as follows:

$$
T(x)=\lambda f(x)
$$

where $f(x)$ characterises the shape of the shear interslice force across the sliding mass and $\lambda$ is a scaling parameter with the dimension of force. This method is also developed within the rigorous context. From equation (50), one obtains

$$
\begin{aligned}
& \Gamma_{1}(x)=0 ; \Gamma_{2}(x)=\lambda f(x) \\
& \Gamma_{1}^{\prime}(x)=0 ; \Gamma_{2}^{\prime}(x)=\frac{\Delta \Gamma_{2}(x)}{\Delta x}
\end{aligned}
$$

\section{Rigorous Janbu method (Janbu, 1954, 1973)}

The rigorous Janbu method considers all the force and moment equilibrium conditions by assuming the location of the line of thrust. Taking moments of forces acting on a typical slice of infinitesimal width at the midpoint of the slice base, one obtains

$$
T(x)=E(x) y_{\mathrm{t}}^{\prime}+h_{\mathrm{t}} E^{\prime}(x)-q_{\mathrm{x}} h(x)+0 \cdot 5 \mathrm{k}_{\mathrm{c}} w(x) h(x)
$$

Thus

$$
\begin{aligned}
& \Gamma_{1}(x)=y_{\mathrm{t}}^{\prime}, \Gamma_{2}(x)=h_{\mathrm{t}} E^{\prime}(x)-q_{\mathrm{x}} h(x)+0 \cdot 5 \mathrm{k}_{\mathrm{c}} w(x) h(x) \\
& \Gamma_{1}^{\prime}(x)=y_{\mathrm{t}}^{\prime \prime}, \Gamma_{2}^{\prime}(x)=\frac{\Delta \Gamma_{2}(x)}{\Delta x}
\end{aligned}
$$

As moment equilibrium has been satisfied through equation (52), only vertical and horizontal force equilibrium equations need to be used for calculating the factor of safety.

\section{NUMERICAL PROCEDURE}

The procedure for computing the factor of safety using the present generalised framework consists of the following steps. 
Step 1. Calculation of normal stress $\sigma_{0}(x)$

Calculate $\sigma_{0}(x)$ using equation (31), in which parameters $\Gamma_{1}, \Gamma_{2}, \Gamma_{1}^{\prime}$ and $\Gamma_{2}^{\prime}$ are determined by equations as indicated in Table 1 (assuming $F_{\mathrm{s} 0}=1$ and $\lambda=0$ in the first step).

Step 2. Calculation of relevant parameters

Calculate the following list of parameters as expressed in Appendix 1:

$$
\begin{aligned}
& A_{1}, A_{1}^{\prime}, A_{2}, A_{2}^{\prime}, A_{3}, A_{3}^{\prime} ; B_{1}, B_{1}^{\prime}, B_{2}, B_{2}^{\prime}, B_{3}, B_{3}^{\prime} ; \\
& D_{1}, D_{2}, D_{3} ; E_{1}, E_{2}, E_{3} ; T_{0}, T_{1}, T_{2} ; S_{0}, S_{1}, S_{2} ; \\
& G_{0}, G_{1}, G_{2} ; t_{0}, t_{1}, t_{2} ; p, q ; p_{1}, q_{1} ; p_{2}, q_{2}
\end{aligned}
$$

\section{Step 3. Calculation of $F_{\mathrm{s}}$}

Calculate $F_{\mathrm{s}}$ using equation (20) for methods 7-11, equation (23) for method 2, equation (26) for methods 3-6 and method 12, and equation (27) for method 1 respectively.

\section{Step 4. Calculation of internal forces}

Calculate $\eta_{1}$ and $\eta_{2}$, using equations (16a) and (16b) for methods 7-11, equation (21a) for method 2, and equation (24a) for methods 3-6 and method 12. For method 1, we have $\eta_{1}=1$ and $\eta_{2}=1$.

Calculate $\sigma(x)$ using equations (6) and (7).

Calculate $\tau(x)$ using equation (1).

Then calculate the internal forces $E(x)$ and $T(x)$ as follows:

$$
\begin{aligned}
& E(x)=E_{\mathrm{a}}+\int_{a}^{x}\left(-\sigma \cdot s^{\prime}+\tau-k_{\mathrm{c}} w+q_{x}\right) \mathrm{d} \varsigma \\
& T(x)=T_{\mathrm{a}}+\int_{a}^{x}\left(\sigma+\tau \cdot s^{\prime}-w-q_{y}\right) \mathrm{d} \varsigma
\end{aligned}
$$

Step 5. Modification of scaling parameter $\lambda$

For rigorous methods of slices, calculate $\lambda$ as follows:

$$
\begin{aligned}
& \lambda=\frac{T\left(x_{\mathrm{m}}\right)}{E\left(x_{\mathrm{m}}\right)} \\
& \text { for method } 7 \\
& \lambda=\frac{T\left(x_{\mathrm{m}}\right)}{E\left(x_{\mathrm{m}}\right) f\left(x_{\mathrm{m}}\right)} \\
& \text { for method } 8 \\
& \lambda=\frac{T\left(x_{\mathrm{m}}\right) F_{\mathrm{s}}}{\left[E\left(x_{\mathrm{m}}\right)-P_{\mathrm{w}}\left(x_{\mathrm{m}}\right)\right] \psi^{\mathrm{v}}\left(x_{\mathrm{m}}\right)+c^{\mathrm{v}}\left(x_{\mathrm{m}}\right) h\left(x_{\mathrm{m}}\right)}
\end{aligned}
$$$$
\text { for method } 9
$$

$$
\lambda=\frac{T\left(x_{\mathrm{m}}\right) F_{\mathrm{s}}}{\left\{\left[E\left(x_{\mathrm{m}}\right)-P_{\mathrm{w}}\left(x_{\mathrm{m}}\right)\right] \psi^{\mathrm{v}}\left(x_{\mathrm{m}}\right)+c^{\mathrm{v}}\left(x_{\mathrm{m}}\right) h\left(x_{\mathrm{m}}\right)\right\} f\left(x_{\mathrm{m}}\right)}
$$

for method 10

$$
\lambda=\frac{T\left(x_{m}\right)}{f\left(x_{m}\right)}
$$

for method 11

in which

$$
x_{\mathrm{m}}=\frac{a+b}{2}
$$

Step 6. Improvement of solution for factor of safety

Repeat steps 1-5 until $F_{\mathrm{s}}$ and/or $\lambda$ converge. On convergence of $F_{\mathrm{s}}$, the values of $\eta_{1}$ and $\eta_{2}$ automatically approach unity, which implies that the assumed normal stress $\sigma_{0}(x)$ at the beginning of the last iteration approximates the final normal stress $\sigma(x)$ well.

A flowchart of the above procedure is schematically presented in Fig. 2.

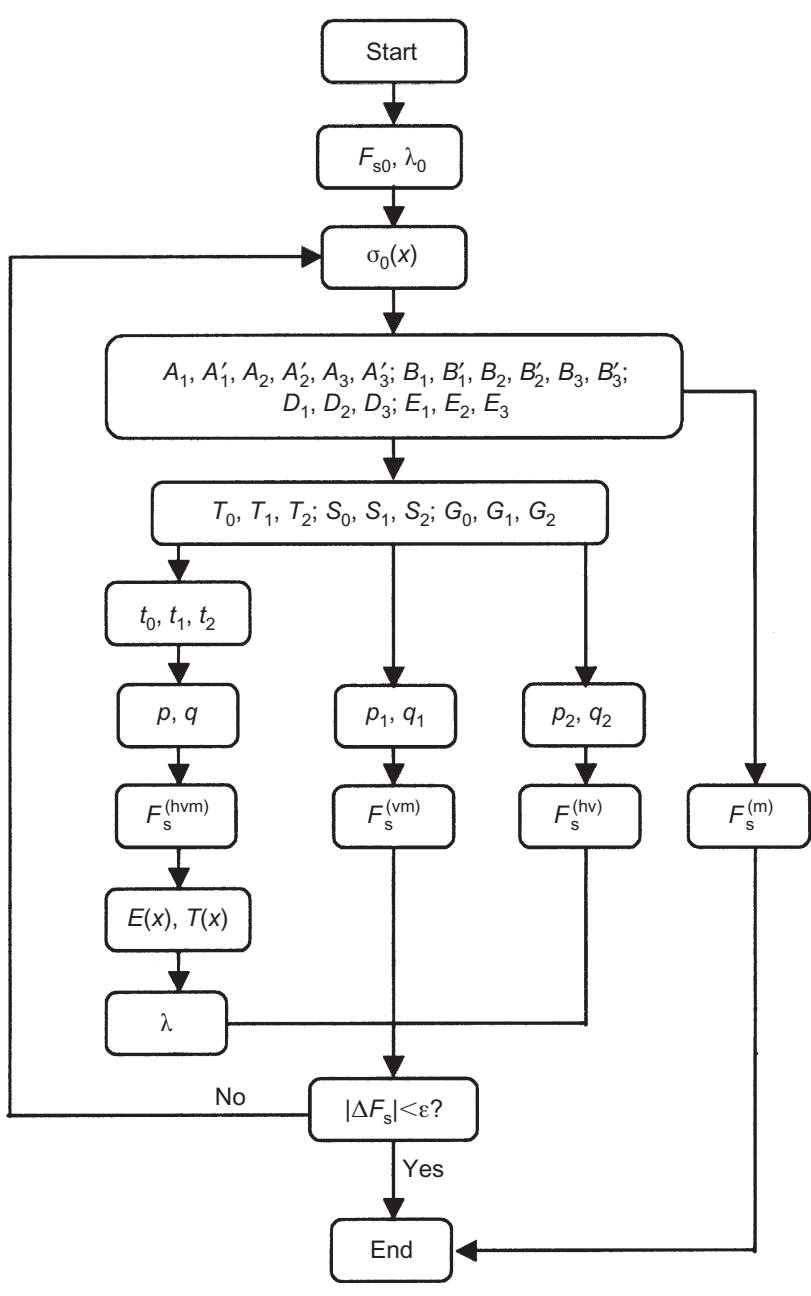

Fig. 2. Flowchart of computation

Some caution is needed when computing these parameters associated with the Corps of Engineers method, the LoweKarafiath method and the rigorous Janbu method. For the two former methods, when the ground surface $g(x)$ or the slip surface $s(x)$ is not smooth, $\Gamma_{1}(x)$ could vary abruptly at vertices, resulting in unreasonably large values of $\Gamma_{1}^{\prime}(x)$ (negative or positive) at these points when the width of slice chosen is small (or the number of slices is large). From equation (31), it can be seen that too large values of $\Gamma_{1}^{\prime}(x)$ (or $\Gamma_{2}^{\prime}(x)$ ) could lead to an unreasonable distribution of initial normal stress $\sigma_{0}(x)$, particularly negative values of $\sigma_{0}$, which are statically invalid. To overcome this numerical difficulty, a smoothing technique is employed to obtain a smooth shape of distribution of $g^{\prime}(x)$ and $s^{\prime}(x)$. This technique is illustrated in Appendix 2. For the rigorous Janbu method, a similar type of numerical difficulty could arise, which often leads to non-convergence of the solution. To solve this problem, a smooth line of thrust is suggested. For example, a Lagrangian function of the order of 3 is adopted:

$$
\begin{aligned}
y_{\mathrm{t}}(x)= & y_{\mathrm{ta}} \cdot \frac{\left(x-a_{1}\right)\left(x-a_{2}\right)(x-b)}{\left(a-a_{1}\right)\left(a-a_{2}\right)(a-b)} \\
& +y_{\mathrm{tb}} \cdot \frac{(x-a)\left(x-a_{1}\right)\left(x-a_{2}\right)}{(b-a)\left(b-a_{1}\right)\left(b-a_{2}\right)} \\
& +y_{\mathrm{t}}\left(a_{1}\right) \cdot \frac{(x-a)\left(x-a_{2}\right)(x-b)}{\left(a_{1}-a\right)\left(a_{1}-a_{2}\right)\left(a_{1}-b\right)} \\
& +y_{\mathrm{t}}\left(a_{2}\right) \cdot \frac{(x-a)\left(x-a_{1}\right)(x-b)}{\left(a_{2}-a\right)\left(a_{2}-a_{1}\right)\left(a_{2}-b\right)}
\end{aligned}
$$


where $a_{1}=a+1 / 3(b-a), a_{2}=a+2 / 3(b-a) ; y_{\mathrm{t}}\left(a_{1}\right)$ and $y_{\mathrm{t}}\left(a_{2}\right)$ may be taken near the lower-third points of the slice boundaries at points $a_{1}$ and $a_{2}$ respectively. In addition, $y_{\mathrm{t}}^{\prime}$ and $y_{\mathrm{t}}^{\prime \prime}$ can be analytically determined by differentiating equation (57), and their values are continuous and smooth. When calculating $E^{\prime}(x)$ the smoothing technique is also used for achieving reasonable results.

For non-rigorous methods of slices, the final normal stress $\sigma(x)$ over the slip surface does not bring the sliding mass into complete equilibrium. The factor of safety thus computed is regarded as less justifiable when compared with those from the rigorous methods. This normal stress distribution can be taken as the initial $\sigma_{0}(x)$, and equation (20) is then used to calculate the factor of safety, which is within the rigorous context because equation (20) satisfies all the equilibrium conditions. In this situation, the values of parameters $\eta_{1}$ and $\eta_{2}$ will differ from unity. Therefore, for non-rigorous methods, we can say that there exist two corresponding factors of safety, one computed with such methods themselves, and the other, recalculated using equation (20), within the rigorous context.

The solution by limit equilibrium method can be definitely regarded as acceptable if the associated internal forces are statically reasonable. Thus checking is often carried out on the internal forces. For non-rigorous methods, the internal forces cannot be statically reasonable as they violate the essential equilibrium conditions. It has been found that unreasonable assumptions regarding internal forces could lead to unreasonable internal forces, even if the overall equilibrium conditions for the sliding mass are completely satisfied.

The internal force is said to be reasonable if four criteria are satisfied:

(a) the effective normal stress along the slip surface is nonnegative

(b) the line of thrust lies within the sliding mass

(c) the effective normal internal forces are non-negative

(d) the local factor of safety along the vertical interfaces of slices is not less than that along the sliding surface.

For rigorous methods of slices except the rigorous Janbu method, the location of the line of thrust, $y_{\mathrm{t}}(x)$, as shown in Fig. 1, is the result of the solution itself, which can be calculated from moment equilibrium for the part of the sliding mass from $a$ to $x$. Such moment equilibrium is given as follows:

$$
\begin{aligned}
& \int_{a}^{x}\left[\left(-\sigma \cdot s^{\prime}+\tau\right) \cdot\left(y_{\mathrm{t}}-s\right)+\left(\sigma+\tau \cdot s^{\prime}-w-q_{y}\right) \cdot(\varsigma-x)\right. \\
& \left.\quad-k_{\mathrm{c}} w\left(y_{\mathrm{t}}-0 \cdot 5 s-0 \cdot 5 g\right)+q_{x}\left(y_{\mathrm{t}}-g\right)\right] \mathrm{d} s \\
& =-T_{\mathrm{a}}(a-x)-E_{\mathrm{a}}\left(y_{\mathrm{t}}-y_{\mathrm{ta}}\right)
\end{aligned}
$$

from which the location of the line of thrust is determined as

$$
y_{\mathrm{t}}(x)=\frac{\int_{a}^{x}\left[\left(-\sigma \cdot s^{\prime}+\tau\right) \cdot s-\left(\sigma+\tau \cdot s^{\prime}-w-q_{y}\right) \cdot(\varsigma-x)\right.}{\int_{a}^{x}\left(-\sigma \cdot s^{\prime}+\tau-k_{\mathrm{c}} w+q_{x}\right) \mathrm{d} \varsigma+E_{\mathrm{a}}}
$$

The local factor of safety along this interface is defined as

$$
F_{s}^{\mathrm{v}}(x)=\frac{\left[E(x)-P_{\mathrm{w}}(x)\right] \psi^{\mathrm{v}}(x)+c^{\mathrm{v}}(x) h(x)}{T(x)}
$$

Unlike $F_{\mathrm{s}}, F_{\mathrm{s}}^{\mathrm{v}}(x)$ may be either positive or negative. According to the fourth criterion of statical reasonableness intro- duced, the ratio of $F_{\mathrm{s}}$ to $F_{\mathrm{s}}^{\mathrm{v}}(x), \rho_{\mathrm{v}}$, should lie in the range -1 to $1:$ that is,

$$
-1 \leqslant \rho_{\mathrm{v}} \leqslant 1
$$

where $\rho_{\mathrm{V}}$ can be regarded as the ratio of local strength mobilisation along the vertical interface with respect to that along the slip surface.

From equation (59), we have

$$
\rho_{\mathrm{v}}=\frac{T(x) F_{\mathrm{s}}}{\left[E(x)-P_{\mathrm{w}}(x)\right] \psi^{\mathrm{v}}(x)+c^{\mathrm{v}}(x) h(x)}
$$

The above four criteria for checking internal stress reasonableness are too stringent for most practical problems. It has been found that the factors of safety with unreasonable internal stresses often differ slightly, considering the inherent uncertainties associated with the soil strength parameters, from those with reasonable internal stresses if available, provided complete equilibrium conditions are satisfied (Duncan, 1996). However, if the factor of safety associated with a method deviates largely from other methods, the feature of internal forces helps to check the reasonableness of the solution.

\section{EXAMPLE STUDIES}

An example slope is studied with two potential slip surfaces: circular and general slip surfaces, as shown in Fig. 3. For illustrative purposes, the two slip surfaces are specified and not associated with the minimum factor of safety. The slope consists of four layers of soil, whose properties are given in Table 2 . The strength of the boundary between layers 3 and 4 is the same as that of layer 3, since it is weaker than layer 4 . The slope is assumed to be under both water pressure and earthquake conditions, with the seismic coefficient taken as $0 \cdot 1$.

Slope stability along the two slip surfaces is analysed using the aforementioned procedure proposed and the 12 methods listed in Table 1. The results are presented in Table 3 and Figs 4-7. A total of 100 vertical slices are used to discretise the sliding mass. The computed factors of safety and associated parameters are listed in Table 3, for the first two steps and the final step at convergence. Note that the tolerance on the difference in $F_{\mathrm{S}}$ between two adjacent steps is taken as 0.001 . For non-rigorous methods, factors of safety computed using equation (20) within the rigorous context are also presented. Comparisons of factors of safety between the various methods of slices are displayed graphically in Figs 4 and 5. The internal force features associated with the 12 methods of slices for the two slip surfaces are plotted in Figs 6 and 7. These features include the location of the line of thrust $y_{\mathrm{t}}(x)$, the total normal stress distribution along the slip surface, the normal and shear interslice forces, and the ratio of local strength mobilisation along the vertical interfaces.

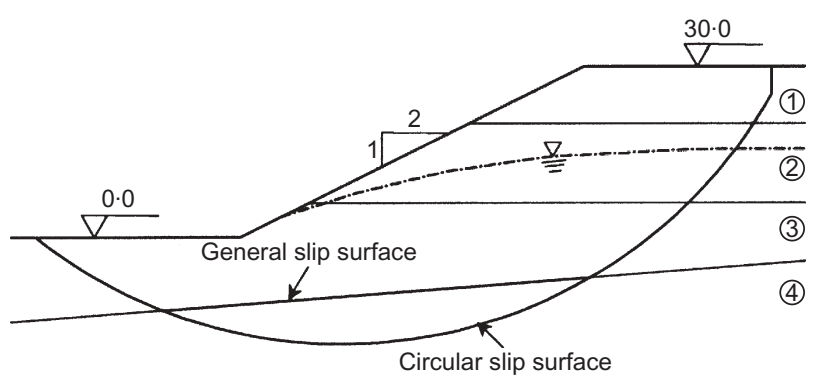

Fig. 3. Profile of example slope 
Table 1. Summary of methods of slices examined

\begin{tabular}{|c|c|c|c|c|c|c|c|c|}
\hline \multirow[t]{2}{*}{ No. } & \multirow[t]{2}{*}{ Method } & \multirow[t]{2}{*}{ Assumption } & \multirow{2}{*}{$\begin{array}{l}\Gamma_{1}(x) \\
\Gamma_{2}(x)\end{array}$} & \multirow{2}{*}{$\begin{array}{l}\Gamma_{1}^{\prime}(x) \\
\Gamma_{2}^{\prime}(x)\end{array}$} & \multirow[t]{2}{*}{$F_{\mathrm{s}}$} & \multicolumn{3}{|c|}{ Equilibrium conditions } \\
\hline & & & & & & Vertical force & Horizontal force & Moment \\
\hline 1 & Ordinary & Eq. (32) & Eq. (33a) & Eq. (33b) & Eq. (27) & & & $\mathrm{C}$ \\
\hline 2 & Simplified Bishop & Eq. (34) & Eq. (35a) & Eq. $(35 b)$ & Eq. (23) & $\mathrm{S}$ & & $\mathrm{C}$ \\
\hline 3 & Simplified Janbu & Eq. (34) & Eq. (35a) & Eq. $(35 b)$ & Eq. (26) & $\mathrm{S}$ & $\mathrm{S}$ & \\
\hline 4 & Corps of Engineers & Eq. (36) & Eq. (37a) & Eq. $37(\mathrm{~b})$ & Eq. (26) & $\mathrm{S}$ & $\mathrm{S}$ & \\
\hline 5 & Lowe \& Karafiath & Eq. (38) & Eq. (39a) & Eq. 39(b) & Eq. (26) & $\mathrm{S}$ & $\mathrm{S}$ & \\
\hline 6 & Sarma I & Eq. (40) & Eq. (41a) & Eq. (41b) & Eq. (26) & $\mathrm{S}$ & $\mathrm{S}$ & \\
\hline 7 & Spencer & Eq. (42) & Eq. (43a) & Eq. (43b) & Eq. (20) & $\mathrm{S}$ & $\mathrm{S}$ & $\mathrm{S}$ \\
\hline 8 & Morgenstern \& Price & Eq. (44) & Eq. (45a) & Eq. (45b) & Eq. (20) & $\mathrm{S}$ & $\mathrm{S}$ & $\mathrm{S}$ \\
\hline 9 & Sarma II & Eq. (46) & Eq. (47a) & Eq. (47b) & Eq. (20) & $\mathrm{S}$ & $\mathrm{S}$ & $\mathrm{S}$ \\
\hline 10 & Sarma III & Eq. (48) & Eq. (49a) & Eq. (49b) & Eq. (20) & $\mathrm{S}$ & S & S \\
\hline 11 & Correia & Eq. $(50)$ & Eq. (51a) & Eq. $(51 b)$ & Eq. $(20)$ & $\mathrm{S}$ & $\mathrm{S}$ & $\mathrm{S}$ \\
\hline 12 & Rigorous Janbu & Eq. (52) & Eq. (53a) & Eq. (53b) & Eq. (26) & $\mathrm{S}$ & $\mathrm{S}$ & AS \\
\hline
\end{tabular}

Note: $\mathrm{C}=$ considered, $\mathrm{S}=$ satisfied; $\mathrm{AS}=$ automatically satisfied.

Table 2. Properties of soils used in example slope

\begin{tabular}{l|c|c|c}
\hline Layer & $\gamma: \mathrm{kN} / \mathrm{m}^{3}$ & $c: \mathrm{kPa}$ & $\phi:$ degrees \\
\hline 1 & $18 \cdot 2$ & 20 & 32 \\
2 & $18 \cdot 0$ & 25 & 30 \\
3 & $18 \cdot 5$ & 40 & 18 \\
4 & $18 \cdot 8$ & 40 & 28 \\
\hline
\end{tabular}

It is shown in Table 3 that the solution is converged within 3-10 iterations with such a small tolerance. At convergence, the parameters $\eta_{1}$ and $\eta_{2}$ almost approach unity, as anticipated theoretically.

It is noteworthy that the solution for factor of safety with the rigorous Janbu method also converged rapidly. In practice, non-convergence is often encountered with this method when using conventional computational procedure. For this method, it is interesting to note that the value of the factor of safety computed with equation (26) is nearly identical to that computed with equation (20), which satisfies overall equilibrium. This is due to the fact that the interslice force relationship, equation (52), originally derived by Janbu, automatically satisfies the moment equilibrium condition.

It is shown in Fig. 4 that, for the circular slip surface, small differences of less than $3 \%$ exist among the values of factors of safety obtained by the rigorous methods of slices. However, for non-circular slip surfaces, significant differences of as much as $11 \%$ are observed among computed factors of safety within the rigorous context. Larger differences in values of factor of safety among non-rigorous methods are observed for both the circular and general slip surfaces.

It is shown in Figs 6 and 7 that the internal force features for most solutions can be regarded as statically reasonable. However, statical unreasonableness is observed in some solutions, although their calculated values of factors of safety are not far from those for which the internal force features are statically reasonable. For example, for method 1 , the line of thrust associated with rigorous solution is beyond the reasonable range. For methods 4 and 5 the distribution of normal stress along the slip surface is somewhat unreasonable since its variation at several points is too abrupt, which may not be acceptable from the point of view of physical intuition. For methods 1, 4 and 12 the values of $\rho_{\mathrm{v}}$ are beyond the reasonable range at some locations.

\section{COMPARISON STUDY}

In order to test the validity of the proposed procedure, a comparison is made with the GLE method (Fredlund \& Krahn, 1977). Fig. 8 shows the slope profile for comparison study purposes. Six cases are considered, which correspond to two slip surfaces and three water conditions respectively. Comparison of the computed factors of safety for this problem is shown in Table 4. It is demonstrated that, for the circular slip surface, essentially identical values of factors of safety are obtained between the present method and those computed by Fredlund \& Krahn (1977) using the GLE method. For the non-circular slip surface, there exist some minor (and practically negligible) differences, possibly due to inexact reproduction of the geometry of the slip surface.

\section{CONCLUDING REMARKS}

A generalised framework of limit equilibrium methods of slices has been proposed in this paper to calculate the factors of safety of slopes. In comparison with those previous approaches that are widely used in practice, the present framework has several advantages, as follows:

(a) The three equilibrium equations are derived based on the normal stress distribution on the slip surface, which is described by the product of the initially assumed distribution and a modified function involving two parameters, $\eta_{1}$ and $\eta_{2}$. The factor of safety is then solved analytically.

(b) The assumptions regarding the interslice forces made by the conventional methods of slices (12 in total) are transformed into a unified expression of normal stress distribution over the slip surface. Thus these conventional methods are incorporated into the present framework.

(c) The solution process for the factor of safety is reasonably straightforward. An assumed initial value of the factor of safety is required, which may be assumed to be unity in most cases. Improved values of factor of safety and the scaling parameter $\lambda$ are automatically yielded in subsequent steps, and a converged solution is rapidly obtained within several iterations.

(d) A smoothing technique is employed to avoid numerical difficulty in the solution process, especially for the rigorous Janbu method, which is often subject to nonconvergence. 
Table 3. Results of calculation for example slope

\begin{tabular}{|c|c|c|c|c|c|c|c|c|c|c|c|}
\hline \multirow[t]{2}{*}{ No. } & \multirow[t]{2}{*}{ Method } & \multicolumn{5}{|c|}{ Circular slip surface } & \multicolumn{5}{|c|}{ General slip surface } \\
\hline & & Step & $F_{\mathrm{s}}$ & $\eta_{1}$ & $\eta_{2}$ & $\lambda$ & Step & $F_{\mathrm{s}}$ & $\eta_{1}$ & $\eta_{2}$ & $\lambda$ \\
\hline \multirow[t]{2}{*}{1} & Ordinary & 1 & 1.066 & & & & 1 & 0.979 & & & \\
\hline & & $\mathrm{R}$ & $1 \cdot 301$ & $1 \cdot 3036$ & $1 \cdot 0490$ & & $\mathrm{R}$ & $1 \cdot 128$ & $1 \cdot 1756$ & $1 \cdot 0872$ & \\
\hline \multirow[t]{4}{*}{2} & Simplified Bishop & 1 & $1 \cdot 280$ & $1 \cdot 0172$ & $1 \cdot 0172$ & & 1 & $1 \cdot 154$ & 1.0093 & 1.0093 & \\
\hline & & 2 & $1 \cdot 278$ & 0.9999 & 0.9999 & & 2 & $1 \cdot 156$ & $1 \cdot 0001$ & $1 \cdot 0001$ & \\
\hline & & $3(\mathrm{C})$ & $1 \cdot 278$ & $1 \cdot 0000$ & $1 \cdot 0000$ & & $3(\mathrm{C})$ & $1 \cdot 156$ & $1 \cdot 0000$ & $1 \cdot 0000$ & \\
\hline & & $\mathrm{R}$ & $1 \cdot 292$ & $1 \cdot 2988$ & 0.7788 & & $\mathrm{R}$ & $1 \cdot 110$ & $1 \cdot 2349$ & $0 \cdot 8322$ & \\
\hline \multirow[t]{4}{*}{3} & Simplified Janbu & 1 & $1 \cdot 138$ & $1 \cdot 0095$ & $1 \cdot 0095$ & & 1 & $1 \cdot 026$ & $1 \cdot 0018$ & $1 \cdot 0018$ & \\
\hline & & 2 & $1 \cdot 106$ & 0.9979 & 0.9979 & & 2 & $1 \cdot 021$ & 0.9996 & 0.9996 & \\
\hline & & $5(\mathrm{C})$ & $1 \cdot 112$ & $1 \cdot 0000$ & $1 \cdot 0000$ & & $4(\mathrm{C})$ & $1 \cdot 022$ & $1 \cdot 0000$ & $1 \cdot 0000$ & \\
\hline & & $\mathrm{R}$ & $1 \cdot 291$ & $1 \cdot 2579$ & $0 \cdot 8226$ & & $\mathrm{R}$ & $1 \cdot 117$ & $1 \cdot 2023$ & $0 \cdot 8672$ & \\
\hline \multirow[t]{4}{*}{4} & Corps of Engineers & 1 & $1 \cdot 138$ & $1 \cdot 0095$ & $1 \cdot 0095$ & & 1 & $1 \cdot 026$ & $1 \cdot 0018$ & $1 \cdot 0018$ & \\
\hline & & 2 & $1 \cdot 440$ & 0.9870 & 0.9870 & & 2 & $1 \cdot 067$ & 0.9998 & 0.9998 & \\
\hline & & $7(\mathrm{C})$ & $1 \cdot 377$ & $1 \cdot 0000$ & $1 \cdot 0000$ & & $5(\mathrm{C})$ & $1 \cdot 059$ & $1 \cdot 0000$ & $1 \cdot 0000$ & \\
\hline & & $\mathrm{R}$ & $1 \cdot 315$ & 0.9352 & $1 \cdot 0523$ & & $\mathrm{R}$ & $1 \cdot 045$ & $0 \cdot 9707$ & $1 \cdot 0212$ & \\
\hline \multirow[t]{4}{*}{5} & Lowe \& Karafiath & 1 & $1 \cdot 138$ & $1 \cdot 0095$ & $1 \cdot 0095$ & & 1 & $1 \cdot 026$ & $1 \cdot 0018$ & $1 \cdot 0018$ & \\
\hline & & 2 & $1 \cdot 316$ & $0 \cdot 9889$ & $0 \cdot 9889$ & & 2 & $1 \cdot 082$ & $0 \cdot 9897$ & $0 \cdot 9897$ & \\
\hline & & $4(C)$ & $1 \cdot 290$ & 0.9999 & 0.9999 & & $4(C)$ & $1 \cdot 077$ & $0 \cdot 9999$ & $0 \cdot 9999$ & \\
\hline & & $\mathrm{R}$ & $1 \cdot 304$ & $1 \cdot 0195$ & $0 \cdot 9850$ & & $\mathrm{R}$ & $1 \cdot 092$ & 1.0337 & $0 \cdot 9760$ & \\
\hline \multirow[t]{4}{*}{6} & Sarma I & 1 & $1 \cdot 138$ & $1 \cdot 0095$ & $1 \cdot 0095$ & & 1 & $1 \cdot 026$ & $1 \cdot 0018$ & $1 \cdot 0018$ & \\
\hline & & 2 & $1 \cdot 465$ & 0.9856 & 0.9856 & & 2 & $1 \cdot 363$ & 0.9822 & 0.9822 & \\
\hline & & $10(\mathrm{C})$ & $1 \cdot 340$ & $1 \cdot 0000$ & $1 \cdot 0000$ & & $10(\mathrm{C})$ & $1 \cdot 229$ & $1 \cdot 0000$ & $1 \cdot 0000$ & \\
\hline & & $\mathrm{R}$ & $1 \cdot 289$ & $0 \cdot 9426$ & $1 \cdot 0450$ & & $\mathrm{R}$ & $1 \cdot 171$ & $0 \cdot 9120$ & $1 \cdot 0655$ & \\
\hline \multirow[t]{3}{*}{7} & Spencer & 1 & $1 \cdot 290$ & $1 \cdot 2228$ & $0 \cdot 8600$ & $0 \cdot 2629$ & 1 & $1 \cdot 118$ & $1 \cdot 1960$ & $0 \cdot 8737$ & $0 \cdot 3170$ \\
\hline & & 2 & $1 \cdot 293$ & 0.9987 & 1.0009 & $0 \cdot 2626$ & 2 & $1 \cdot 171$ & $0 \cdot 9211$ & 1.0528 & $0 \cdot 2538$ \\
\hline & & $3(\mathrm{C})$ & $1 \cdot 293$ & $1 \cdot 0001$ & $0 \cdot 9999$ & $0 \cdot 2628$ & $7(\mathrm{C})$ & $1 \cdot 155$ & $1 \cdot 0013$ & $0 \cdot 9991$ & $0 \cdot 2554$ \\
\hline \multirow[t]{3}{*}{8} & Morgenstern \& Price & 1 & $1 \cdot 290$ & $1 \cdot 2228$ & $0 \cdot 8600$ & $0 \cdot 2629$ & 1 & $1 \cdot 118$ & $1 \cdot 1960$ & 0.8737 & $0 \cdot 3170$ \\
\hline & & 2 & $1 \cdot 300$ & 1.0639 & 0.9488 & $0 \cdot 3353$ & 2 & $1 \cdot 119$ & 1.0205 & $0 \cdot 9840$ & $0 \cdot 3485$ \\
\hline & & $4(C)$ & $1 \cdot 303$ & 1.0000 & $1 \cdot 0000$ & 0.3383 & $3(\mathrm{C})$ & $1 \cdot 119$ & $1 \cdot 0011$ & 0.9991 & 0.3508 \\
\hline \multirow[t]{3}{*}{9} & Sarma II & 1 & $1 \cdot 290$ & $1 \cdot 2228$ & $0 \cdot 8600$ & $0 \cdot 8718$ & 1 & $1 \cdot 118$ & $1 \cdot 1960$ & $0 \cdot 8737$ & $0 \cdot 8330$ \\
\hline & & 2 & $1 \cdot 289$ & $0 \cdot 9660$ & 1.0258 & $0 \cdot 7675$ & 2 & $1 \cdot 171$ & $0 \cdot 9118$ & $1 \cdot 0603$ & $0 \cdot 6511$ \\
\hline & & $3(\mathrm{C})$ & $1 \cdot 289$ & 1.0055 & 0.9959 & $0 \cdot 7845$ & $8(\mathrm{C})$ & $1 \cdot 154$ & 0.9987 & 1.0009 & 0.6466 \\
\hline \multirow[t]{3}{*}{10} & Sarma III & 1 & $1 \cdot 290$ & $1 \cdot 2228$ & $0 \cdot 8600$ & $0 \cdot 8718$ & 1 & $1 \cdot 118$ & $1 \cdot 1960$ & $0 \cdot 8737$ & $0 \cdot 8330$ \\
\hline & & 2 & $1 \cdot 301$ & 1.0638 & 0.9489 & $1 \cdot 1265$ & 2 & $1 \cdot 111$ & 1.0305 & 0.9763 & 0.9545 \\
\hline & & $4(C)$ & $1 \cdot 303$ & 1.0032 & 0.9974 & $1 \cdot 1374$ & $3(\mathrm{C})$ & $1 \cdot 112$ & 1.0018 & 0.9984 & $0 \cdot 9648$ \\
\hline \multirow[t]{3}{*}{11} & Correia & 1 & $1 \cdot 290$ & $1 \cdot 2228$ & $0 \cdot 8600$ & $2562 \cdot 7$ & 1 & $1 \cdot 119$ & $1 \cdot 1960$ & 0.8737 & $1608 \cdot 4$ \\
\hline & & 2 & $1 \cdot 283$ & $0 \cdot 9684$ & 1.0259 & $2290 \cdot 2$ & 2 & $1 \cdot 120$ & 0.9936 & 1.0050 & $1557 \cdot 0$ \\
\hline & & $4(C)$ & $1 \cdot 284$ & 0.9992 & 1.0007 & $2291 \cdot 7$ & $3(\mathrm{C})$ & $1 \cdot 119$ & 1.0008 & 0.9994 & $1563 \cdot 0$ \\
\hline \multirow{4}{*}{12} & Rigorous Janbu & 1 & $1 \cdot 138$ & 1.0095 & 1.0095 & & 1 & $1 \cdot 026$ & $1 \cdot 0018$ & $1 \cdot 0018$ & \\
\hline & & 2 & 1.336 & $1 \cdot 0020$ & $1 \cdot 0020$ & & 2 & $1 \cdot 145$ & $1 \cdot 0021$ & $1 \cdot 0021$ & \\
\hline & & $5(\mathrm{C})$ & $1 \cdot 318$ & 1.0001 & $1 \cdot 0001$ & & $6(C)$ & $1 \cdot 137$ & 1.0001 & 1.0001 & \\
\hline & & $\mathrm{R}$ & $1 \cdot 317$ & 0.9987 & $1 \cdot 0010$ & & $\mathrm{R}$ & $1 \cdot 136$ & 0.9984 & $1 \cdot 0012$ & \\
\hline
\end{tabular}

Note: $\mathrm{C}=$ converged value, $\mathrm{R}=$ rigorous value.

The centre of the circle is chosen as the common centre for the two slip surfaces.

The interslice force functions for methods 8,10 and 11 are in the form of a half-sine.

(e) The factors of safety associated with the non-rigorous methods of slices are less justifiable than those associated with the rigorous methods. However, we can adjust their normal stress distribution to bring the sliding mass into complete equilibrium conditions, resulting in factors of safety within the rigorous context.

It should be pointed out that the limit equilibrium solution is neither upper- nor lower-bound for the actual solution. However, many solutions based on the various limit equilibrium methods within the rigorous context provide a rather narrow range of possible solutions. Although the simplified Bishop method is not rigorous, it is still applicable to circular slip surfaces, owing to its simplicity and nearly identical solutions with other rigorous methods. For non-circular slip surfaces, the Morgenstern-Price method and the Spencer method are most useful as they provide consistent factors of safety and involve very few numerical difficulties.
Moreover, slope stability analysis often entails another important issue: location of the critical slip surface that is associated with the minimum factor of safety. The present study has not addressed this issue, which has been studied by many researchers (e.g. Duncan, 1996). Herein all the methods of slices are brought into a generalised framework. However, for the same slope, different methods of slices could have different locations of the critical slip surfaces. Locating the critical slip surfaces within such a generalised framework will be a subject of future studies by the authors.

\section{ACKNOWLEDGEMENTS}

This study was financially supported by the Research Grants Council of Hong Kong, and the Jockey Club Research and Information Centre for Landslip Prevention and Land Development at the University of Hong Kong. Their support is gratefully acknowledged. 


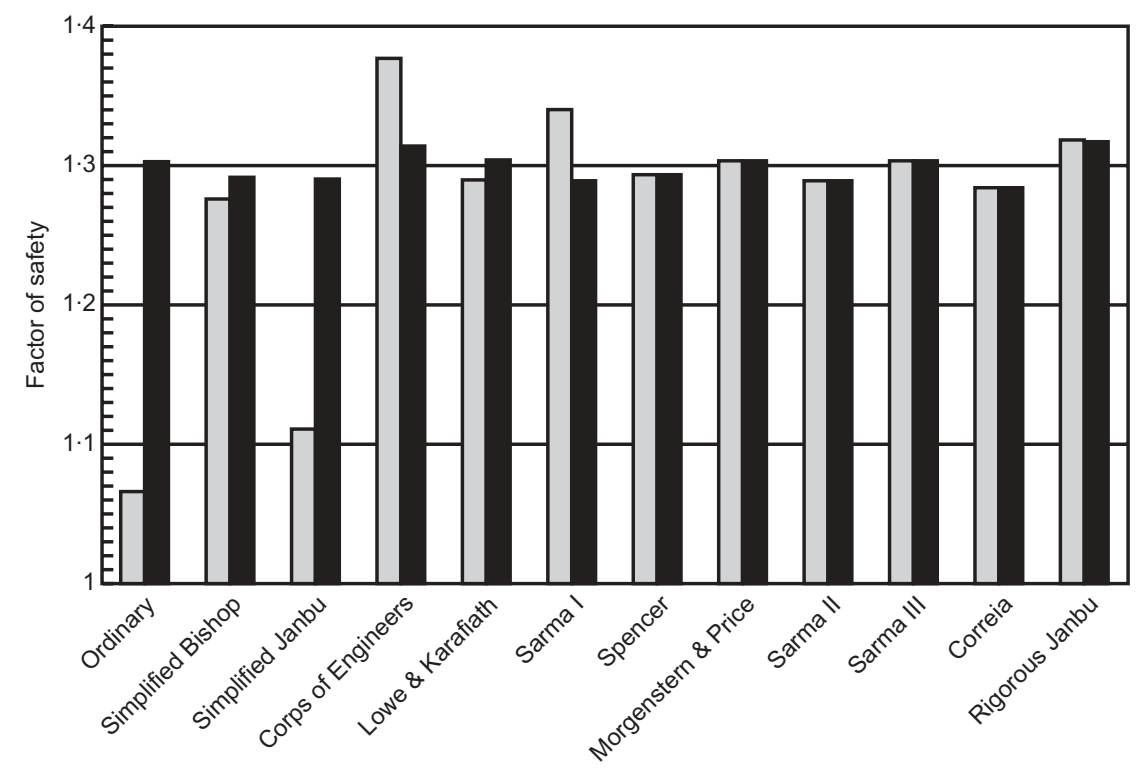

Conventional

Rigorous

Fig. 4. Comparison of factors of safety: circular slip surface

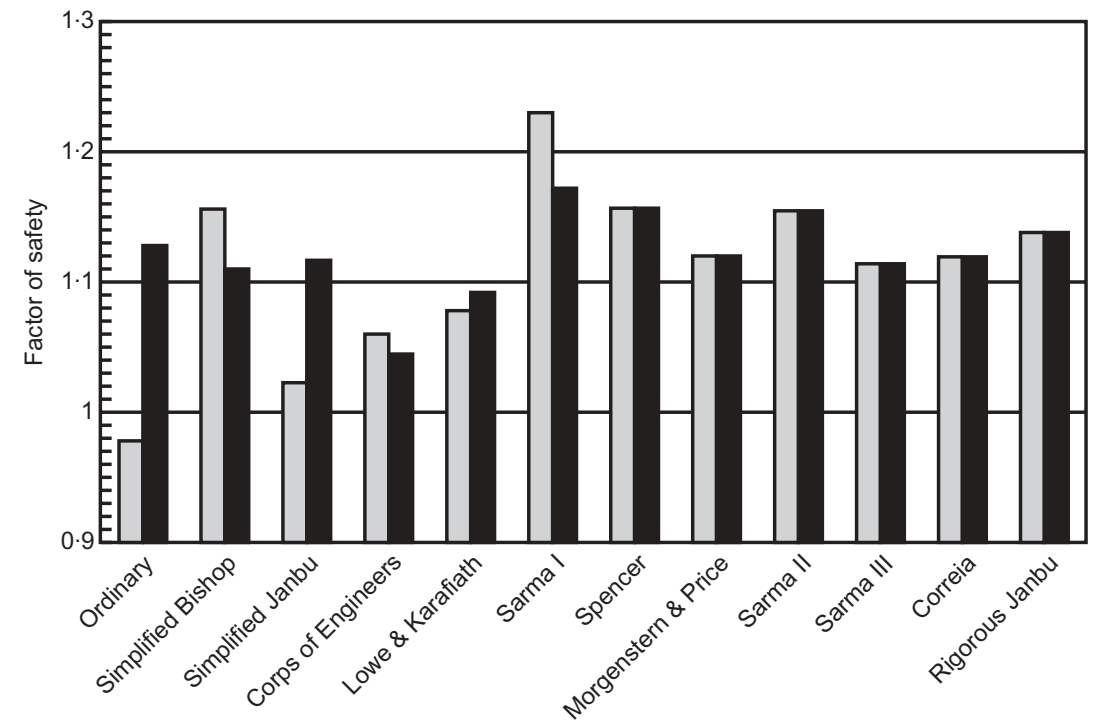

Conventional

Rigorous

Fig. 5. Comparison of factors of safety: general slip surface

APPENDIX 1. PARAMETERS RELATED TO

COMPUTATION OF FACTOR OF SAFETY

$$
\begin{aligned}
& A_{1}=-\int_{a}^{b} s^{\prime} \xi_{1} \sigma_{0} \mathrm{~d} x ; A_{1}^{\prime}=\int_{a}^{b} \psi \xi_{1} \sigma_{0} \mathrm{~d} x \\
& A_{2}=-\int_{a}^{b} s^{\prime} \xi_{2} \sigma_{0} \mathrm{~d} x ; A_{2}^{\prime}=\int_{a}^{b} \psi \xi_{2} \sigma_{0} \mathrm{~d} x \\
& A_{3}=F_{x} ; A_{3}^{\prime}=\int_{a}^{b}(u \psi-c) \mathrm{d} x
\end{aligned}
$$

$$
\begin{aligned}
& B_{1}=\int_{a}^{b} \xi_{1} \sigma_{0} \mathrm{~d} x ; B_{1}^{\prime}=\int_{a}^{b} s^{\prime} \psi \xi_{1} \sigma_{0} \mathrm{~d} x \\
& B_{2}=\int_{a}^{b} \xi_{2} \sigma_{0} \mathrm{~d} x ; B_{2}^{\prime}=\int_{a}^{b} s^{\prime} \psi \xi_{2} \sigma_{0} \mathrm{~d} x \\
& B_{3}=F_{y} ; B_{3}^{\prime}=\int_{a}^{b} s^{\prime}(u \psi-c) \mathrm{d} x \\
& D_{1}=\int_{a}^{b} \sigma_{0} \xi_{1} \psi r_{\tau} \mathrm{d} x ; D_{2}=\int_{a}^{b} \sigma_{0} \xi_{2} \psi r_{\tau} \mathrm{d} x ; D_{3}=\int_{a}^{b}(-u \psi+c) r_{\tau} \mathrm{d} x
\end{aligned}
$$



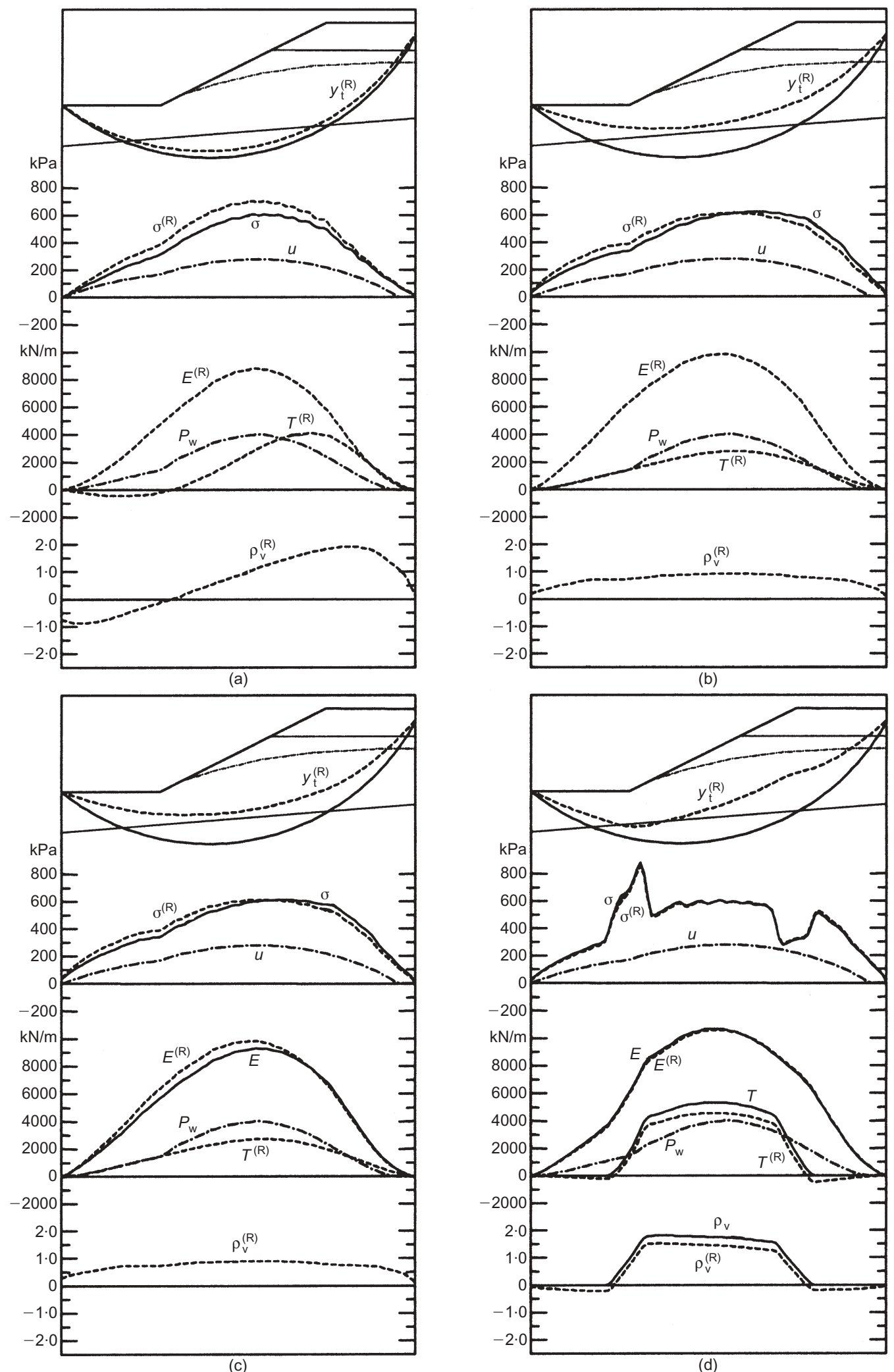

Fig. 6. Internal forces distribution (circular slip surface): (a) method 1, Ordinary; (b) method 2, simplified Bishop; (c) method 3, simplified Janbu; (d) method 4, Corps of Engineers; (e) method 5, Lowe \& Karafiath; (f) method 6, Sarma I; (g) method 7, Spencer; (h) method 8, Morgenstern \& Price; (i) method 9, Sarma II; (j) method 10, Sarma III; (k) method 11, Correia; (l) method 12, rigorous Janbu

$$
\begin{aligned}
& E_{1}=-\int_{a}^{b} \sigma_{0} \xi_{1} r_{\sigma} \mathrm{d} x ; E_{2}=-\int_{a}^{b} \sigma_{0} \xi_{2} r_{\sigma} \mathrm{d} x ; E_{3}=M_{\mathrm{c}} \\
& T_{0}=A_{3} B_{2}-A_{2} B_{3}
\end{aligned}
$$

$$
\begin{aligned}
& T_{1}=A_{3} B_{2}^{\prime}+A_{3}^{\prime} B_{2}-A_{2} B_{3}^{\prime}-A_{2}^{\prime} B_{3} \\
& T_{2}=A_{3}^{\prime} B_{2}^{\prime}-A_{2}^{\prime} B_{3}^{\prime} \\
& S_{0}=A_{1} B_{3}-A_{3} B_{1}
\end{aligned}
$$



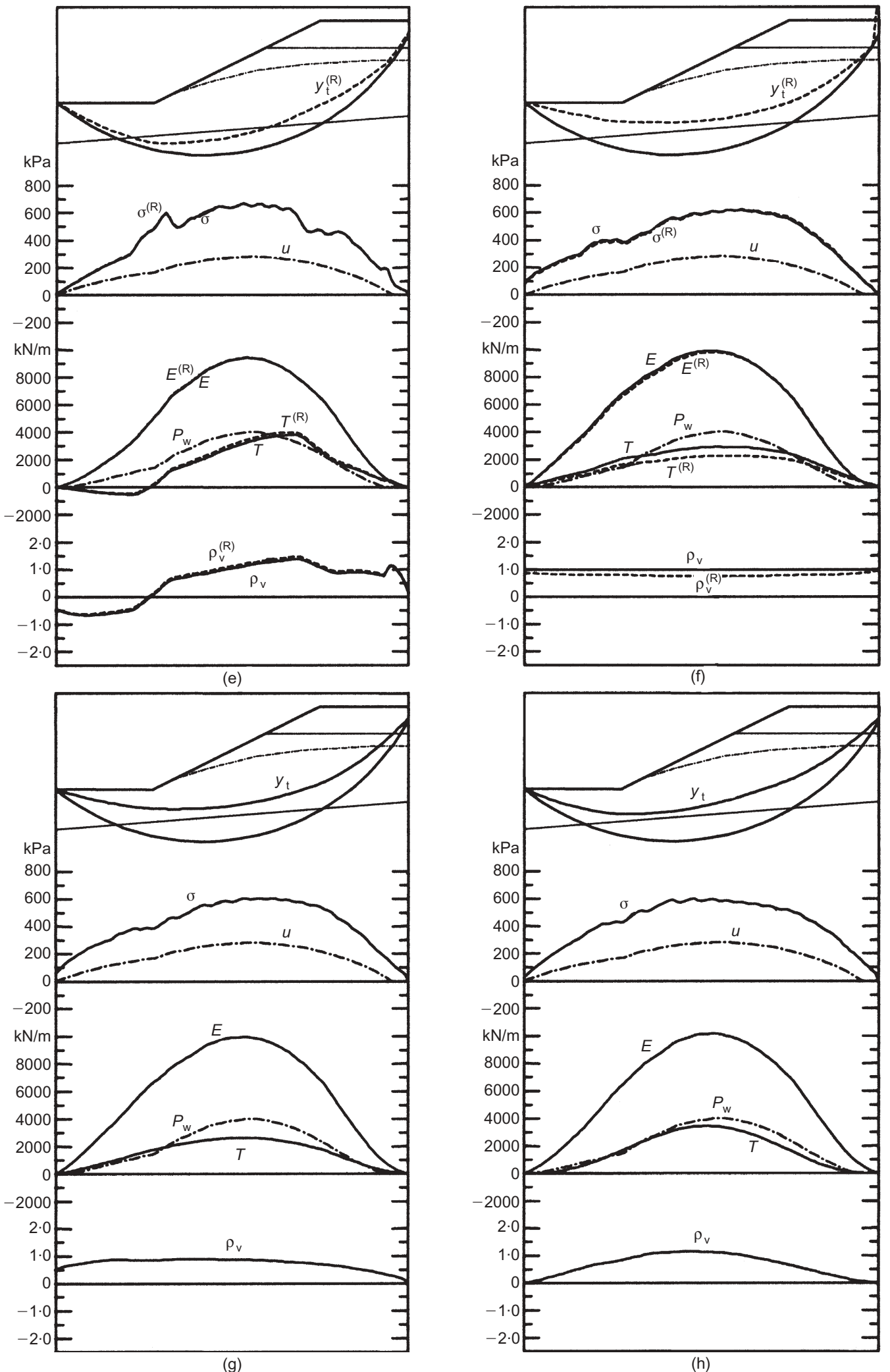

Fig. 6. (continued)

$$
\begin{aligned}
& S_{1}=A_{1} B_{3}^{\prime}+A_{1}^{\prime} B_{3}-A_{3} B_{1}^{\prime}-A_{3}^{\prime} B_{1} \\
& S_{2}=A_{1}^{\prime} B_{3}^{\prime}-A_{3}^{\prime} B_{1}^{\prime} \\
& G_{0}=A_{1} B_{2}-A_{2} B_{1} \\
& G_{1}=A_{1} B_{2}^{\prime}+A_{1}^{\prime} B_{2}-A_{2} B_{1}^{\prime}-A_{2}^{\prime} B_{1}
\end{aligned}
$$

(68b) 

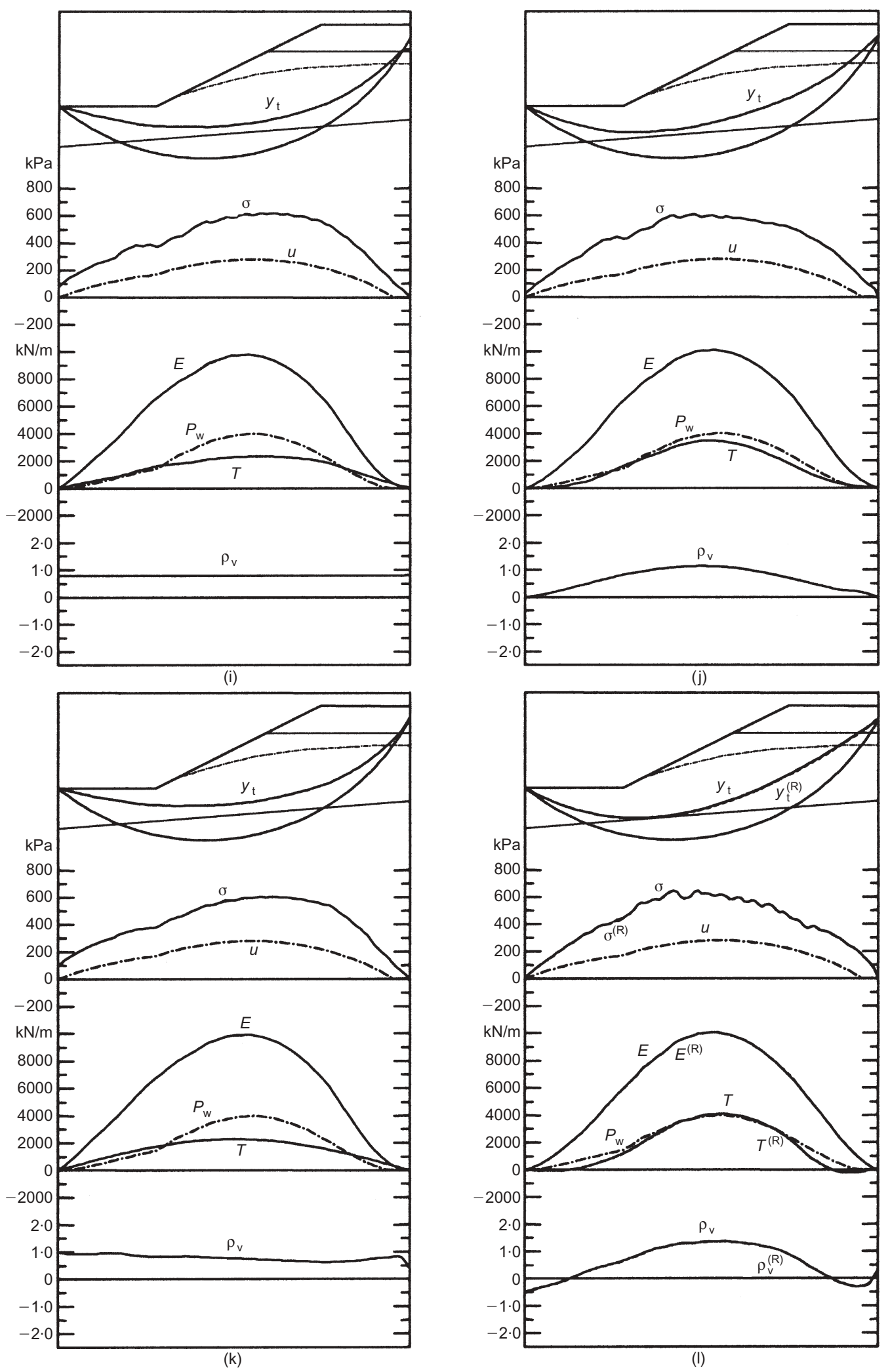

Fig. 6. (continued)

$t_{1}=\frac{E_{1} T_{2}+E_{2} S_{2}+E_{3} G_{2}-D_{1} T_{1}-D_{2} S_{1}-D_{3} G_{1}}{E_{1} T_{0}+E_{2} S_{0}+E_{3} G_{0}}$

$t_{2}=\frac{E_{1} T_{1}+E_{2} S_{1}+E_{3} G_{1}-D_{1} T_{0}-D_{2} S_{0}-D_{3} G_{0}}{E_{1} T_{0}+E_{2} S_{0}+E_{3} G_{0}}$

$p=-\frac{t_{2}^{2}}{3}+t_{1}$ (69b)

(69c)

(70a) $q=-\frac{1}{27} t_{2}^{3}-\frac{1}{3} t_{1} t_{2}+t_{0}$

$$
p_{1}=\frac{\left(E_{1}+E_{2}\right) B_{3}^{\prime}+E_{3}\left(B_{1}^{\prime}+B_{2}^{\prime}\right)-\left(D_{1}+D_{2}\right) B_{3}-\left(B_{1}+B_{2}\right) D_{3}}{\left(E_{1}+E_{2}\right) B_{3}+E_{3}\left(B_{1}+B_{2}\right)}
$$





(c)

(d)

Fig. 7. Internal forces distribution (general slip surface): (a) method 1, Ordinary; (b) method 2, simplified Bishop; (c) method 3, simplified Janbu; (d) method 4, Corps of Engineers; (e) method 5, Lowe \& Karafiath; (f) method 6, Sarma I; (g) method 7, Spencer; (h) method 8, Morgenstern \& Price; (i) method 9, Sarma II; (j) method 10, Sarma III; (k) method 11, Correia; (l) method 12, rigorous Janbu 


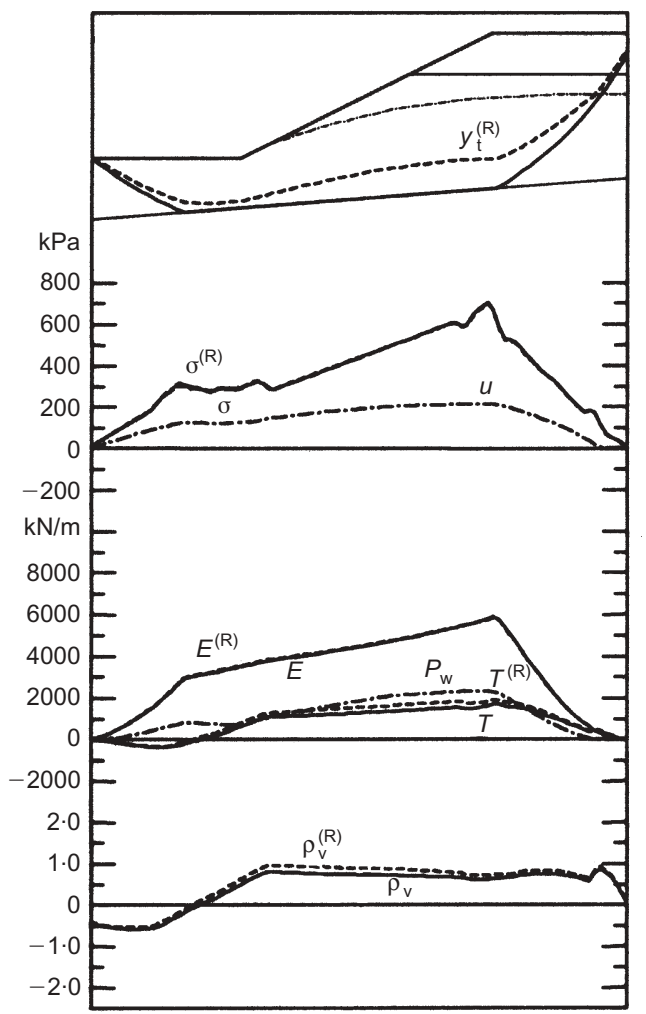

(e)

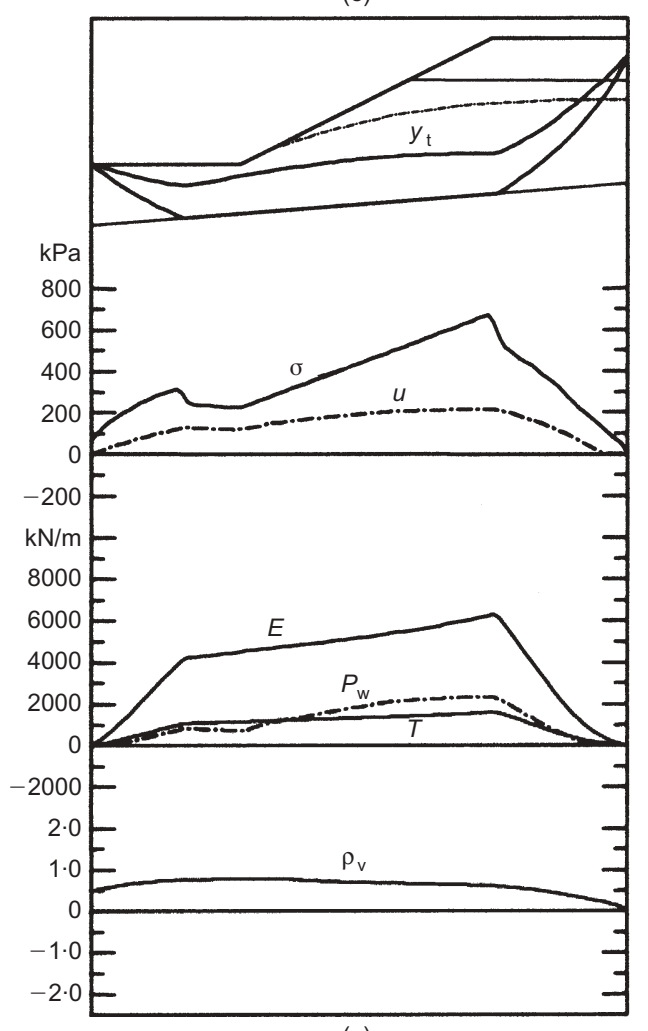

(g)
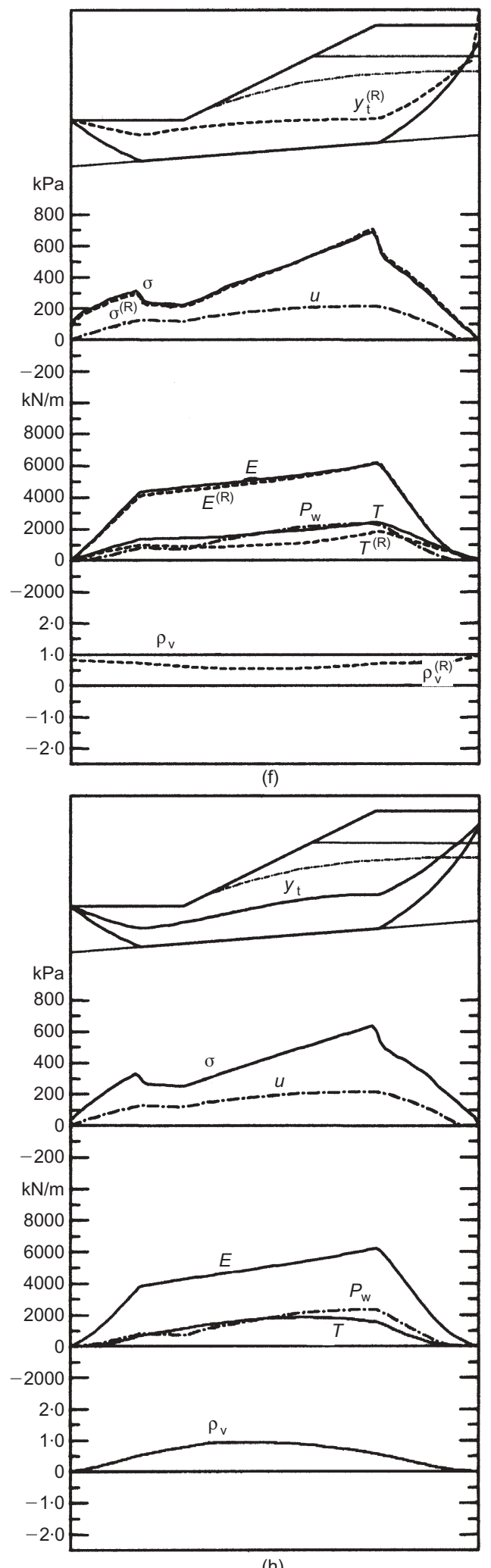

(h)

Fig. 7. (continued)

$q_{2}=\frac{\left(A_{1}^{\prime}+A_{2}^{\prime}\right) B_{3}^{\prime}-A_{3}^{\prime}\left(B_{1}^{\prime}+B_{2}^{\prime}\right)}{\left(A_{1}+A_{2}\right) B_{3}-A_{3}\left(B_{1}+B_{2}\right)}$
APPENDIX 2. SMOOTHING TECHNIQUE

Assume values of function $y(x)$ at a series of points distributed between $x=a$ and $x=b$, as shown in Fig. 9. Now determine the numerical value of derivative $y^{\prime}\left(x_{0}\right)$ at point $x_{0}$. 

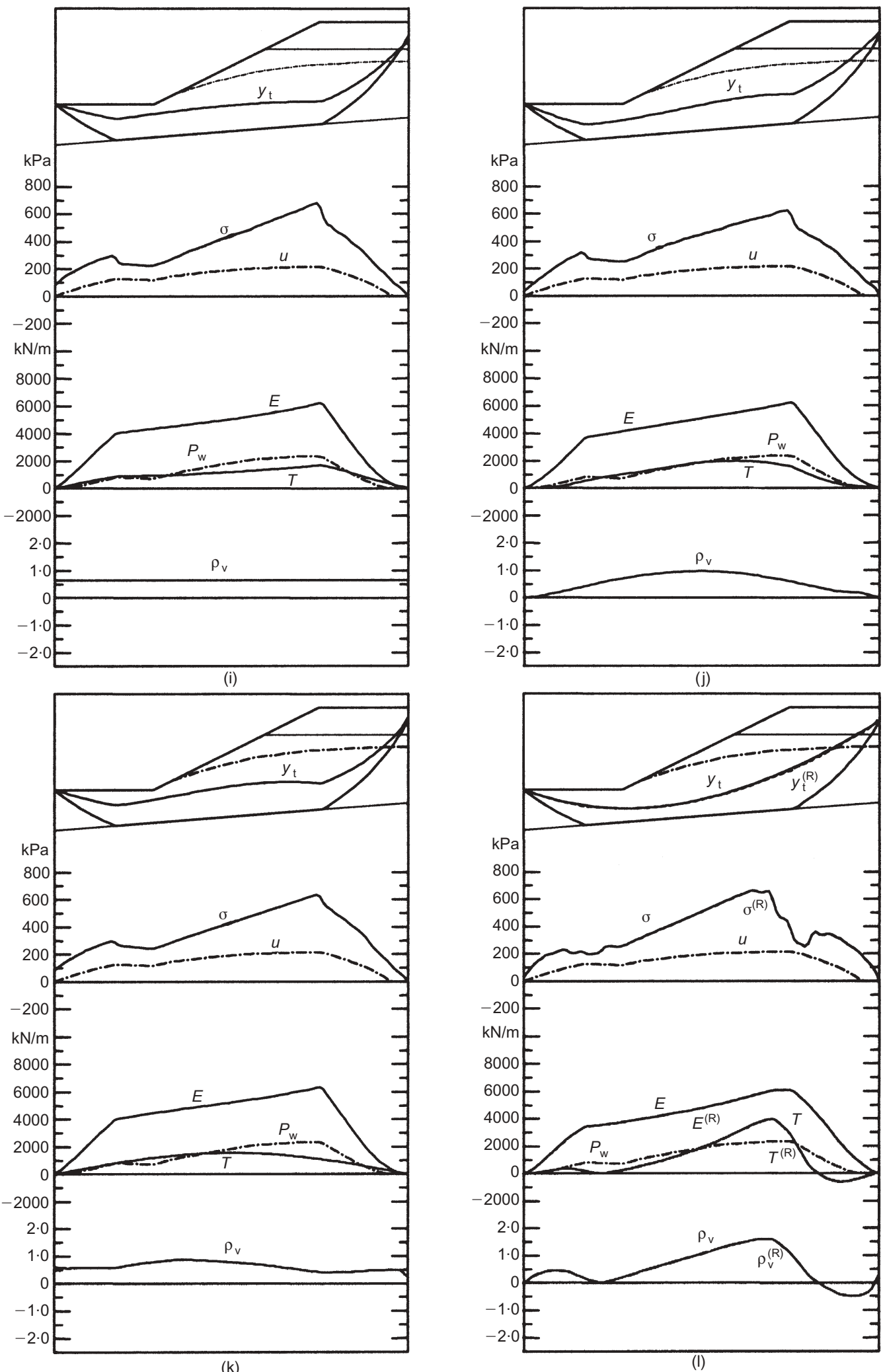

Fig. 7. (continued)

When point $x_{0}$ is located so far from the end points, $x=a$ and $x=b$, that an interval $\left[x_{1}, x_{2}\right]$ with a distance $\Delta$ can bracket it at the midpoint, in which $\Delta \cong(b-a) / 10$, the derivative is numerically determined as

$$
y^{\prime}\left(x_{0}\right)=\frac{y_{2}-y_{1}}{\Delta}
$$

When the distance between point $x_{0}$ and the end point is less than half of $\Delta$-that is, $\Delta_{1}<0.5 \Delta$ or $\Delta_{2}<0.5 \Delta$, as shown in Fig. 9the derivative is numerically computed with the following equation:

$$
y^{\prime}\left(x_{0}\right)=\frac{\Delta_{2}}{\Delta} \frac{y_{0}-y_{1}}{\Delta_{1}}+\frac{\Delta_{1}}{\Delta} \frac{y_{2}-y_{0}}{\Delta_{2}}
$$




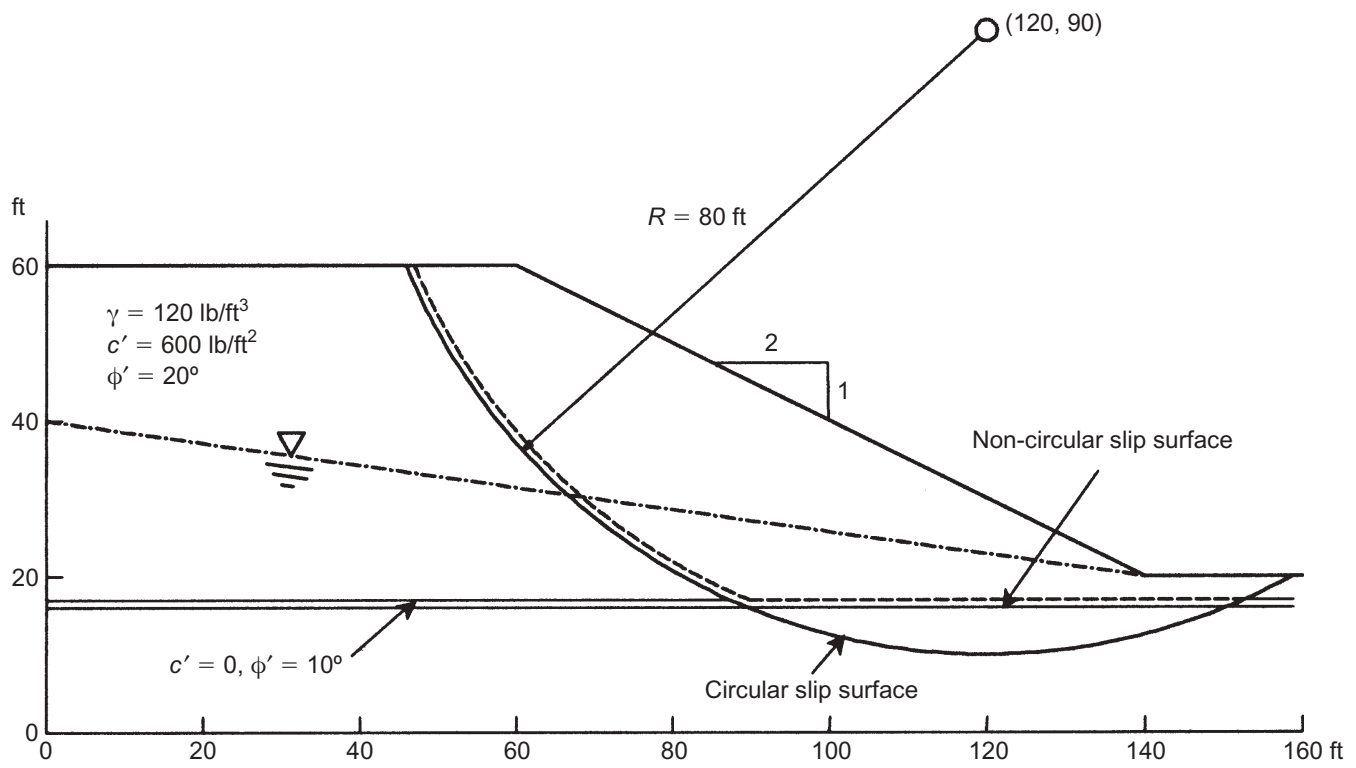

Fig. 8. Example for comparison study (after Fredlund \& Krahn, 1977)

Table 4. Comparison of computed factors of safety for the example used by Fredlund \& Krahn (1977)

\begin{tabular}{|c|c|c|c|c|c|c|c|c|}
\hline \multirow{2}{*}{$\begin{array}{l}\text { Case } \\
\text { No. }\end{array}$} & \multirow[t]{2}{*}{ Case } & \multirow{2}{*}{$\begin{array}{c}\text { Ordinary } \\
F_{\mathrm{s}}\end{array}$} & \multirow{2}{*}{$\begin{array}{c}\text { Simplified } \\
\text { Bishop } \\
F_{\mathrm{s}} \\
\end{array}$} & \multirow{2}{*}{$\begin{array}{c}\text { Rigorous } \\
\text { Janbu } \\
F_{\mathrm{s}} \\
\end{array}$} & \multicolumn{2}{|c|}{ Spencer } & \multicolumn{2}{|c|}{ Morgenstern-Price } \\
\hline & & & & & $F_{\mathrm{s}}$ & $\lambda$ & $F_{\mathrm{s}}$ & $\lambda$ \\
\hline 1 & $\begin{array}{l}\text { Circular slip surface without } \\
\text { water pressure }\end{array}$ & $\begin{array}{l}1.928 \\
1.931^{*} \\
2 \cdot 064^{* \mathrm{R}}\end{array}$ & $\begin{array}{l}2 \cdot 080 \\
2 \cdot 078^{*} \\
2 \cdot 071^{* \mathrm{R}}\end{array}$ & $\begin{array}{l}2 \cdot 008 \\
2 \cdot 080^{*}\end{array}$ & $\begin{array}{l}2 \cdot 073 \\
2 \cdot 075^{*}\end{array}$ & $\begin{array}{l}0 \cdot 237 \\
0 \cdot 258^{*}\end{array}$ & $\begin{array}{l}2 \cdot 076 \\
2 \cdot 074^{*}\end{array}$ & $\begin{array}{l}0 \cdot 318 \\
0 \cdot 318^{*}\end{array}$ \\
\hline 2 & $\begin{array}{l}\text { Non-circular slip surface without } \\
\text { water pressure }\end{array}$ & $\begin{array}{l}1 \cdot 288 \\
1 \cdot 300^{*} \\
1 \cdot 378^{* \mathrm{R}}\end{array}$ & $\begin{array}{l}1 \cdot 377 \\
1 \cdot 380^{*} \\
1 \cdot 366^{* \mathrm{R}}\end{array}$ & $\begin{array}{l}1 \cdot 432 \\
1 \cdot 375^{*}\end{array}$ & $\begin{array}{l}1 \cdot 373 \\
1 \cdot 381^{*}\end{array}$ & $\begin{array}{l}0 \cdot 185 \\
0 \cdot 189^{*}\end{array}$ & $\begin{array}{l}1 \cdot 370 \\
1 \cdot 371^{*}\end{array}$ & $\begin{array}{l}0 \cdot 187 \\
0 \cdot 228^{*}\end{array}$ \\
\hline 3 & $\begin{array}{l}\text { Circular slip surface with water } \\
\text { pressures defined by } r_{\mathrm{u}}=0.25\end{array}$ & $\begin{array}{l}1 \cdot 607 \\
1 \cdot 610^{*} \\
1 \cdot 749^{* \mathrm{R}}\end{array}$ & $\begin{array}{l}1 \cdot 766 \\
1 \cdot 761^{*} \\
1 \cdot 756^{* \mathrm{R}}\end{array}$ & $\begin{array}{l}1 \cdot 708 \\
1 \cdot 765^{*}\end{array}$ & $\begin{array}{l}1 \cdot 761 \\
1 \cdot 760^{*}\end{array}$ & $\begin{array}{l}0 \cdot 255 \\
0 \cdot 250^{*}\end{array}$ & $\begin{array}{l}1 \cdot 764 \\
1 \cdot 759^{*}\end{array}$ & $\begin{array}{l}0 \cdot 304 \\
0 \cdot 309^{*}\end{array}$ \\
\hline 4 & $\begin{array}{l}\text { Non-circular slip surface with } \\
\text { water pressures defined by } \\
r_{\mathrm{u}}=0 \cdot 25\end{array}$ & $\begin{array}{l}1 \cdot 029 \\
1 \cdot 038^{*} \\
1 \cdot 110^{* \mathrm{R}}\end{array}$ & $\begin{array}{l}1 \cdot 124 \\
1 \cdot 118^{*} \\
1 \cdot 107^{* \mathrm{R}}\end{array}$ & $\begin{array}{l}1 \cdot 162 \\
1 \cdot 160^{*}\end{array}$ & $\begin{array}{l}1 \cdot 118 \\
1 \cdot 119^{*}\end{array}$ & $\begin{array}{l}0 \cdot 139 \\
0 \cdot 164^{*}\end{array}$ & $\begin{array}{l}1 \cdot 118 \\
1 \cdot 109^{*}\end{array}$ & $\begin{array}{l}0 \cdot 130 \\
0 \cdot 195^{*}\end{array}$ \\
\hline 5 & $\begin{array}{l}\text { Circular slip surface with water } \\
\text { pressures defined by piezometric } \\
\text { line }\end{array}$ & $\begin{array}{l}1 \cdot 693 \\
1 \cdot 698^{*} \\
1 \cdot 822^{* \mathrm{R}}\end{array}$ & $\begin{array}{l}1 \cdot 834 \\
1 \cdot 832^{*} \\
1 \cdot 828^{* \mathrm{R}}\end{array}$ & $\begin{array}{l}1 \cdot 776 \\
1.836^{*}\end{array}$ & $\begin{array}{l}1 \cdot 830 \\
1 \cdot 831^{*}\end{array}$ & $\begin{array}{l}0 \cdot 247 \\
0 \cdot 240^{*}\end{array}$ & $\begin{array}{l}1 \cdot 832 \\
1 \cdot 831^{*}\end{array}$ & $\begin{array}{l}0 \cdot 290 \\
0 \cdot 298^{*}\end{array}$ \\
\hline 6 & $\begin{array}{l}\text { Non-circular slip surface with } \\
\text { water pressures defined by } \\
\text { piezometric line }\end{array}$ & $\begin{array}{l}1 \cdot 171 \\
1 \cdot 192^{*} \\
1 \cdot 255^{* \mathrm{R}}\end{array}$ & $\begin{array}{l}1 \cdot 248 \\
1 \cdot 260^{*} \\
1 \cdot 251^{* \mathrm{R}}\end{array}$ & $\begin{array}{l}1.298 \\
1.299^{*}\end{array}$ & $\begin{array}{l}1 \cdot 245 \\
1 \cdot 261^{*}\end{array}$ & $\begin{array}{l}0 \cdot 121 \\
0 \cdot 144^{*}\end{array}$ & $\begin{array}{l}1 \cdot 245 \\
1 \cdot 254^{*}\end{array}$ & $\begin{array}{l}0 \cdot 101 \\
0 \cdot 165^{*}\end{array}$ \\
\hline
\end{tabular}

No superscript: Fredlund \& Krahn (1977).

* Present method.

* $\mathrm{R}$ Factor of safety in rigorous context modified from the non-rigorous one.

The interslice function used in the Morgenstern-Price method is half-sine.

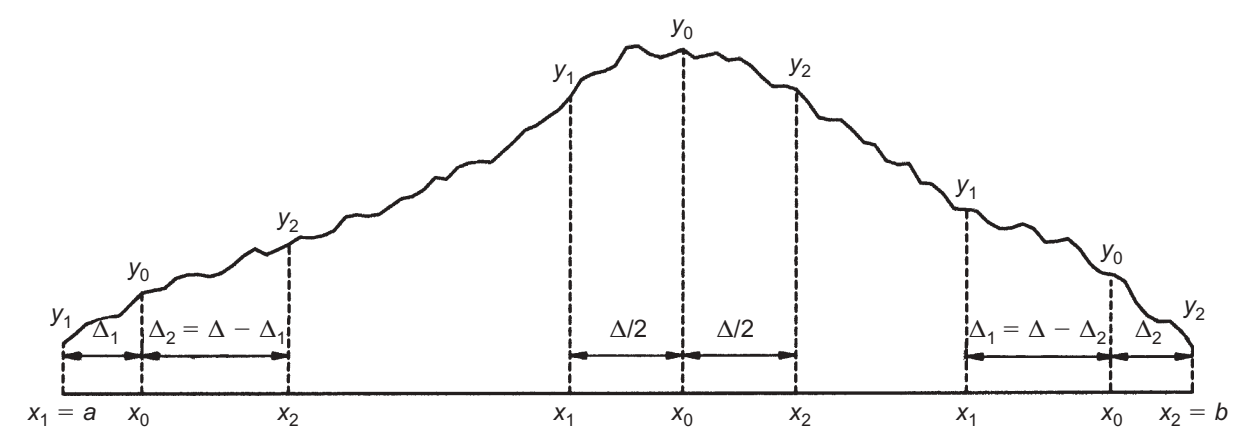

Fig. 9. Determination of derivative $y^{\prime}\left(x_{0}\right)$ 
NOTATION

$F_{s}$ factor of safety

$\mathrm{k}_{\mathrm{c}}$ horizontal seismic coefficient

$\mathrm{g}(\mathrm{x})$ ordinate of the ground surface

$\mathrm{s}(\mathrm{x})$ ordinate of the slip surface

$\mathrm{y}_{\mathrm{t}}(\mathrm{x})$ ordinate of the line of thrust

$\mathrm{E}(\mathrm{x})$ normal interslice force

$\mathrm{T}(\mathrm{x})$ shear interslice force

$\mathrm{P}_{\mathrm{w}}(\mathrm{x})$ resultant of pore pressure along the interface of slices

$\mathrm{q}_{\mathrm{x}}(\mathrm{x}), \mathrm{q}_{\mathrm{y}}(\mathrm{x})$ horizontal and vertical external pressure on the ground

$E_{a}, T_{a}, E_{b}, T_{b}$ external forces at the two ends of the sliding body

$\mathrm{w}(\mathrm{x})$ self-weight of slice of unit width

$\left(\mathrm{x}_{\mathrm{c}}, \mathrm{y}_{\mathrm{c}}\right)$ coordinates of the centre of the moment

$f(x)$ shape of interslice force function

$h(x)$ height of slice

$h_{t}(x)$ height of line of thrust

$\mathrm{a}, \mathrm{b}$ abscissa of the two ends of the sliding body

$\sigma$ total normal stress over the slip surface

$\sigma_{0} \quad$ initial total normal stress over the slip surface

$\tau$ shear stress over the slip surface

$\mathrm{u}$ pore pressure at the slip surface

c cohesion in terms of effective or total stress as the case may be

$\phi$ internal friction angle in terms of effective or total stress as the case may be

$\psi$ friction coefficient

$\xi$ modifying function

$\eta_{1}, \eta_{2}$ auxiliary unknowns

$\lambda$ scaling factor in interslice force function

$\Gamma_{1}, \Gamma_{2}$ coefficients defining the interslice force relationship

\section{REFERENCES}

Bishop, A. W. (1955). The use of the slip circle in the stability analysis of earth slopes. Géotechnique 5, No. 1, 7-17.

Ching, R. K. H. \& Fredlund, D. G. (1983). Some difficulties associated with the limit equilibrium method of slices. Can. Geotech. J. 20, No. 4, 661-672.

Correia, R. M. (1988). A limit equilibrium method of slope stability analysis. Proc. 5th Int. Symp. Landslides, Lausanne, 595-598.
Duncan, J. M. (1996). State of the art: limit equilibrium and finiteelement analysis of slopes. J. Geotech. Engng, ASCE 122, No. 7, 577-596.

Espinoza, R. D., Bourdeau, P. L. P. C. \& Muhunthan, B. (1994). Unified formulation for analysis of slopes with general slip surface. J. Geotech. Engng, ASCE 120, No. 7, 1185-1204.

Fellenius, W. (1936). Calculation of the stability of earth dams. Proc. 2nd Congr. Large Dams, Washington 4, 445-462.

Fredlund, D. G. \& Krahn, J. (1977). Comparison of slope stability methods of analysis. Can. Geotech. J. 14, No. 3, 429-439.

Janbu, N. (1954). Application of composite slip surface for stability analysis. Proceedings of European conference on stability of earth slopes, Stockholm, vol. 3, pp. 43-49.

Janbu, N. (1973). Slope stability computations. In Embankment Dam Engineering, Casagrande Memorial Volume (eds E. Hirschfield and S. Poulos), pp. 47-86. New York: Wiley.

Janbu, N., Bjerrum, L. \& Kjaernsli, B. (1956). Soil mechanics applied to some engineering problems. Norwegian Geotechnical Institute Publication 16, Oslo, Norway.

Kim, J., Salgado, R. \& Yu, H. S. (1999). Limit analysis of soil slopes subjected to pore-water pressures. J. Geotech. Geoenviron. Engng, ASCE 125, No. 1, 49-58.

Lowe, J. \& Karafiath, L. (1960). Stability of earth dams upon drawdown. Proc. 1st Pan-Am. Conf. on Soil Mech. Found. Engng., Mexico City 2, 537-552.

Morgenstern, N. R. \& Price, V. E. (1965). The analysis of the stability of general slip surfaces. Géotechnique 15, No. 1, 79-93.

Nonveiller, E. (1965). The stability analysis of slopes with a slip surface of general shape. Proc. 5th Conf. Soil Mech. Found. Engng, Montreal 2, 522-525.

Sarma, S. K. (1973). Stability analysis of embankments and slopes. Géotechnique 23, No. 3, 423-433.

Sarma, S. K. (1979). Stability analysis of embankments and slopes. J. Geotech. Engng Div., ASCE 105, No. 2, 1511-1524.

Spencer, E. (1967). A method of analysis of the stability of embankments assuming parallel interslice forces. Géotechnique 17, No. 1, 11-26.

Spencer, E. (1973). The thrust line criterion in embankment stability analysis. Géotechnique 23, No. 1, 85-100.

US Army Corps of Engineers (1967). Stability of slopes and foundations: Engineering manual. Vicksburg, MS.

Yu, H. S., Salgado, R., Sloan, S. W. \& Kim, J. M. (1998). Limit analysis versus limit equilibrium for slope stability. J. Geotech. and Geoenviron. Engng, ASCE 124, No. 1, 1-11. 